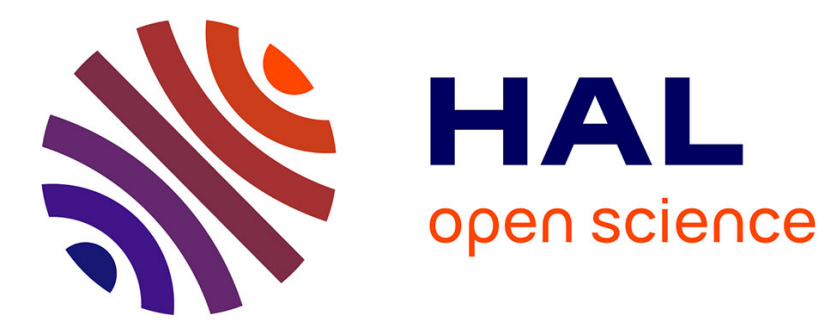

\title{
Le baptistère Saint-Jean de Poitiers
}

François Eygun

\section{To cite this version:}

François Eygun. Le baptistère Saint-Jean de Poitiers. Gallia - Fouilles et monuments archéologiques en France métropolitaine, 1964, 22 (1), pp.137-171. 10.3406/galia.1964.2192 . hal-01934376

\section{HAL Id: hal-01934376 https://hal.science/hal-01934376}

Submitted on 25 Feb 2020

HAL is a multi-disciplinary open access archive for the deposit and dissemination of scientific research documents, whether they are published or not. The documents may come from teaching and research institutions in France or abroad, or from public or private research centers.
L'archive ouverte pluridisciplinaire HAL, est destinée au dépôt et à la diffusion de documents scientifiques de niveau recherche, publiés ou non, émanant des établissements d'enseignement et de recherche français ou étrangers, des laboratoires publics ou privés.

\section{(이) $\$$}

Distributed under a Creative Commons Attribution - NonCommercial - NoDerivatives| 4.0 


\title{
LE BAPTISTÈRE SAINT-JEAN DE POITIERS
}

\author{
par François EYGUN
}

Le baptistère Saint-Jean qui a fait couler beaucoup d'encre au cours du $\mathrm{xIx}^{\mathrm{e}}$ siècle n'avait guère, avant le milieu du xvir ${ }^{e}$, attiré l'attention des amateurs de monuments anciens. Avant la Révolution, la ville de Poitiers contenait plus de vingt paroisses et de nombreux édifices monastiques ou conventuels, dont certains très importants qui minimisaient l'intérêt du plus vénérable monument chrétien poitevin encore debout. La tradition y retrouvait l'ancien baptistère de l'église de Poitiers, baptisterium beati Joannis Baptislae, dit au XIII ${ }^{\mathrm{e}}$ siècle le cartulaire de l'évêché de Poitiers, rédigé sous l'impulsion du bienheureux Gauthier de Bruges. d'où le nom de Grand Gauthier ${ }^{1}$ attribué au manuscrit conservé à la Bibliothèque municipale. Au milieu du xvıne siècle le savant dom Fonteneau atteste la tradition du concile de Mâcon, de 585, qui fixait les dates de Pâques legitimum dies baptismi et de la Pentecôte pour les fêtes normales du baptème. Celle de saint Jean-Baptiste, le baptiseur du Christ, s'y ajoute très naturellement plus tard. En la vigile de ces jours, l'évêque se rendait au baptistère. Le 10 juin 1661 encore, cet érudit atteste que "les chanoines de Saint-Pierre (la cathédrale) s'y transportent processionnellement aux mêmes jours pour y faire publiquement bénédiction des fonts, qu'ils y vont la veille de la Saint Jean chanter les matines, le lendemain la grand messe et qu'ils y tiennent leur synode des curés de la ville deux fois l'année ${ }^{2}$.

Le Moyen Age ne sut pas lui conserver son éclat, puisqu'en 1450, le corps de ville ordonne une quête dans toutes les paroisses " pour les réparations de l'église de Monseigneur Sainct Jehan Baptiste, qui est choite toute en ruyne ". En effet, à mesure que le baptême était donné dans d'autres églises, les revenus du baptistère et son rôle diminuaient d'autant. Peut-être pensa-t-on remédier à cet état de chose en l'érigeant en paroisse ; ̀̀ vrai dire, son statut paraît incertain : en 1096, le desservant est qualifié d'abbé et le baptistère d'abbaye, réalité ou expression honorifique en raison de son passé liturgique? Le titre sera seulement supprimé en 1758 , les biens étant rattachés à $N$. D. la Grande. Dès 1386, un rôle donne la paroisse comme unie à celle de St Hilaire entre Églises ${ }^{3}$. Cependant ses registres, qui vont de 1453 à 1791 , ne mentionnent mariages et enterrements qu'à partir de 1638. Mais ce ne fut jamais qu'un pis aller, car il ne s'y trouvait que 25 communiants et l'on n'y disait la messe que le jour de la Saint-Jean. Sa pauvreté, en tous cas, explique le triste état dans lequel se présentait l'église à la veille de la Révolution.

Cependant, le monument était alors déjà célèbre. Jusqu'au milieu du xviI è siècle sa destination n'avait pas suscité de discussions. Il était l'ancien baptistère de la ville. Il fallut l'intervention de l'érudition pour troubler ces notions simples et traditionnelles. Ce fut le savant Dreux du Radier qui, dans le Journal Historique sur les matières du temps, dit Journal de Verdun ${ }^{5}$, d'ailleurs imprimé à Paris, déclara y voir un monument funéraire où Marcus Censorius Pavius, propréteur d'Aquitaine,

(1) Bibliothèque municipale de Poitiers, Ms LIX de Dom Fonteneau, p. 129 et 364.

(2) Bibliothèque municipale de Poitiers, Ms III de Dom Fonteneau p. 237 et t. LXXVII, p. 189-193.

(3) Arch. Hist. du Poitou, t. XLVI, p. 292, n. 12 et Mém. Soc. antiquaires de l'Ouest, 1840, p. 417-418.

(4) La Liborlítre, Vieux souvenirs de Poitiers d'avant 1789, Poitiers, 1846, in-12, p. 46.

(5) T. 11 de 1750 ; p. 430 et 1751 . 
aurait enlerré sa femme Varenilla. Frappé par son caractère romain, il s'appuyait en outre sur l'existence dans la cathédrale d'un magnifique linteau de marbre blanc, où une inscription faisait allusion à cette morte, Claudia Varenilla, que les commentateurs peu épigraphistes appellent assez singulièrement Cluarenilla. Une tradition non prouvée prétendait que cette inscription provenait de Saint-Jean. Dans le mème Journal de Verdun, en 1750, paraitt une réfutation par dom Fonteneau : l'érudit bénédictin, dont l'esprit clair a presque toujours pressenti la vérité des questions historiques et archéologiques poitevines, reprenait la thèse primitive. Dom Martène, un peu indécis sur l'origine de l'édifice, remarque la forme en croix de son plan. L'abbé Lebeuf, essayant de concilier les deux théories en présence, y voit un monument paien transformé en baptistère chrétien ${ }^{6}$. Les deux opinions vont s'affronter durant un siècle et donner naissance à la ridicule appellation de "Temple Saint-Jean ".

La célébrité du monument et les discussions archéologiques sur sa destination ne l'empêcheront pas d'être attribué comme bien national au citoyen Lafond mais il fut distrait de la liste des immeubles à démolir par décision des administrateurs de la Vienne en date du 13 messidor an IV (1 er juillet 1796), sur l'intervention du citoyen Mazet, ci-devant bénédictin devenu bibliothécaire de la ville. Attribué aux hospices pendant une vingtaine d'années, dépôt de matériaux, fourneau populaire en 1812, abandonné en 1820 à un fondeur de cloches qui détériora les marches et le fond de la piscine, son état laissait fort à désirer en 1821. La Société académique des arts ne put en obtenir la jouissance et un arrèté préfectoral du 30 janvier 1822 le rendit à l'administration diocésaine, à charge de l'entretenir, ce qui ne dut pas ruiner celle-ci. Une autre menace que la vétusté apparaissait aussi grave. Le percement de la rue prévue pour aboutir au Pont Neuf avait été adjugé à l'architecte Vétault fils, technicien qui méprisait profondément les styles anciens. Ayant traversé l'orangerie. les cloîtres et les terrasses de Sainte-Croix, il allait atteindre en 1834 le baptistère que la municipalité voulait racheter pour le détruire. Une pétition, les démarches pressantes de la Société des antiquaires de l'ouest et de son président, de Chergé, appuyées par le rapport de Vitet, les instances de Caumont, obtinrent enfin que le tracé de la rue fût dévié et, en 1835, l'achat du monument par l'État et un crédit de $5.725 \mathrm{~F}$ pour les réparations urgentes. En 1836, il était mis à la disposition de la Socièté des antiquaires de l'ouest qui en fit d'abord son musée lapidaire.

Toutes ces péripéties n'avaient point clos les controverses sur la destination originelle de l'édifice. Pourtant, les fouilles très précises faites en 1803 par le commissaire des guerres Siauve ${ }^{7}$. qui, cherchant le tombeau de Claudia Varenilla, trouva la piscine baptismale, et ses excellentes observations auraient dû clore le débat pour l'essentiel : mais lui-mème, impressionné par la thèse de l'abbé Lebeuf, reprit l'idée mitigée du temple transformé en baptistère. Il est regrettable cependant que les auteurs qui ont étudié l'édifice n'aient pas prèté plus d'altention à ses remarques, notamment au sujet de la piscine qu'il a connue intacte. De Caumont, publiant en 1830 son Cours: d'archéologie monumentale, $\mathrm{y}$ voit dès l'origine un monument chrétien, oratoire et baptistère, ce qui a, d'après lui, déterminé sa forme. Mais Mangon de la Lande, le fondateur de la Société des antiquaires de l'ouest, reprend avec vigueur la thèse du tombeau de Varenilla. Mérimée s'y laissa entraîner. L'auteur de la Vénus d'Ille y trouvait peut-ètre une résonnance en accord avec ses goûts littéraires. Dans ses Noles d'un voyage dans l'ouest de la France, en 1836, il voyait dans la piscine une loge pour recevoir l'urne cinéraire de la jeune morte romaine et se complaisait visiblement à cette interprétation romantique.

La remise en état du monument par les soins nécessaires de l'architecte Joly-Leterme, qui déblaya le sol surhaussé de $0,91 \mathrm{~m}$ et restaura l'ensemble, fit changer Mérimée d'avis. Dans sa grande monographie, le Temple Saint-Jean à Poitiers, il expose les résultats obtenus par le restaurateur,

(6) Cette indécision est encore parfois de mise. Voir notamment BréH Lr, L'Arl en France, des invasions arabes à l'époque romane, p. 72 et Pey Cadafalch, L'Arl wisigothique, Paris, 1961, p. 39. Ce dernier compare la silhouette de St-Fructueux de Montelios au tombeau de Galla Placidia el à "l'église Saint-Jean " qu'il croit avoir été primitivement un tombeau dans lequel on a installé un baptistère au $w^{\mathbf{e}}$ siècle.

(7) Mémoire sur les antiquiles du Poilou. 
publie ses plans et admet qu'il s'agit incontestablement d'un baptistère. C'est aussi ce qu'avait dit la clairvoyante monographie de Jules Gailhabaud, parue dans ses Monuments anciens et modernes en 1853, et ce que répétera la petite plaquette d'Émile Espérandieu (1890). Le P. de la Croix donnait en 1904, dans son Élude sommaire du Baptislère Saint-Jean, l'historique du monument et le résultat des fouilles menées par lui à partir de 1890. Son travail parut suffisamment explicite pour que les conclusions en fussent adoptées par Émile Ginot dans son Guide (1934) et pendant près d'un demi siècle. Le fougueux jésuite nous mettait devant le schéma suivant: Piscine, jer étage des murs de la cella: ive siècle. Alors existait une autre cella de dimensions identiques, à l'ouest de l'édifice qui était entouré, selon ses fouilles, d'une série de salles aux formes singulières qu'on essaya d'expliquer de façon peu convaincante. Au viI ${ }^{\mathrm{e}}$ siècle, vers la fin du baptême par immersion, se fit la restauration du bâtiment. Celui-ci est surélevé à partir du premier étage. Trois absidioles sont ajoutées, celle de l'est, octogonale à l'intérieur, en trapèze à l'extérieur ; les deux autres, carrées. Puis, au $\mathrm{XI}^{\mathrm{e}}$ ou XII $\mathrm{XI}^{\mathrm{e}}$ siècle, la cella ouest est démolie et reconstruite sous la forme actuelle, pentagonale. Les absidioles en hémicycle seraient aussi romanes. Tel était l'état de la question.

Mais, voici qu'en 1951, lors du Congrès de la Société française d'archéologie, M. Jean Hubert, alléguant une phrase du rapport non publié de l'architecte Joly-Leterme, de 1865, appuyée sur de savantes comparaisons de plans, proposait une théorie nouvelle. Considérant que les deux cellae rectangulaires, de dimensions identiques, révélées par les fouilles devaient être antérieures à la piscine, il crut reconnaitre une cathédrale double du ive siècle, comme il en a été signalé notamment " en Istrie, en Italie septentrionale, en Gaule et en Rhénanie "; et le baptistère qui est généralement accolé à ces édifices aurait été logé dans l'une des salles annexes rencontrées par les fouilles du P. de la Croix, à l'est de l'édifice. Au vile siècle, une modification du monument l'aurait transformé en baptistère alors que les salles annexes étaient abandonnées. La piscine aurait été construite à ce moment ainsi que les absides quadrangulaires. En effet, une phrase de l'architecte Joly-Leterme déclarait que tout le sol du monument était recouvert d'un béton gris, spécialement depuis l'absidiole mérovingienne de l'est jusqu'à la piscine avec laquelle il faisait corps, déterminant du même coup une date commune pour ces deux éléments. Par ailleurs, s'appuyant sur un article de Mlle Denise Fossard sur les chapiteaux de marbre du viI ${ }^{\mathbf{e}}$ siècle $^{y}$, M. J. Hubert considérait comme erronée la datation du rve siècle des parties du plan du P. de la Croix où étaient figurées colonnes et baies du monument.

Sur ces entrefaites, la Société des antiquaires de l'ouest nous demandait de rééditer le guide du baptistère Saint-Jean, celui d'E. Ginot étant épuisé. Devant les théories inconciliables du P. de la Groix et de M. J. Hubert, il fallait demander l'autorisation de procéder à des sondages dans le monument. La question du béton gris venant de l'abside et faisant corps avec la piscine nous paraissait spécialement devoir être vérifiée. Nous espérions en même temps retrouver à sa surface des traces de mosaïques antiques vues par Joly-Leterme et dont quelques smalts sont conservés au Musée de l'Échevinage.

Le bâtiment avait subi au cours de sa longue existence bien des modifications ${ }^{10}$. Les premières images qui le représentent sont les dessins du comédien Baumesnil vers 1760 ou 1770 (fig. 1). Ils constituent quelques pages d'un manuscrit de la Bibliothèque municipale de Poitiers et l'encre

(8) L'article donnant les théories de M. Jean Ilubert a été publié dans Cahiers archéologiques, VI, 1952, p. 135. Étant le dernier travail publié sur la question, ses conclusions furent reproduites dans A. Katchatrian, Les Baptistères palénchrétiens, p. 118. Abandonnant depuis, pour l'absidıle est, la datation au vil ${ }^{\mathbf{e}}$ siècle sur laquelle il avait établi sa théorie de 1951, M. J. Hubert, au congrès du Haut Moyen Age de 1961, fixait cette fois sa date au xir ${ }^{e}$ siècle.

(9) Cahiers Archéologiques, II, 1945, p. 68 et s.

(10) L'orientation du baptistère, celle de la cathédrale ou de Sainte-Radegonde ne sont pas est-ouest, mais N.-E.-S.-O., qui parait avoir été l'orientation des édifices romains du quartier. Nous garderons cependant pour plus de clarté l'orientation traditionnelle pour nos descriptions. 
affaiblie de ce curieux homme à la vision déformée par de singuliers partis pris a viré à la sepia. Les quatre côtés et le plan sont figurés de façon suffisamment reconnaissables. Nous n'avons pas d'enseignements particuliers à tirer de cet ensemble. Nous y retrouvons, avec des inexactitudes assurément car le narthex est transformé en porche, mais néanmoins très semblable, le monument que nous connaissons. L'absidiole sud en forme de ruche d'abeille que les dessinateurs figurent jusque vers 1830 y est nettement marquée. La façade nord ne possède déjà plus la sienne sur le plan annexe. Un dessin (fig. 2) du lithographe Chalopin, de Caen, qu'on peut approximativement dater des environs de 1820 , nous offre le même aspect du côté sud avec sa bizarre absidiole en demi coupole. La lithographie de C. Bonnord, imprimée à Niort, postérieure à la transformation du baptistère en Musée en 1836, ne figure plus que l'arc de jonction de la cella et de l'absidiole sud. Un jardin entouré de murs régnait autour de l'absidiole est, enfouie dans la verdure qui la masquera jusqu'à la restauration du monument. C'est le même aspect qui est donné avec plus de détails et de meilleures proportions par un crayon au Musée de Châtellerault (fig. 3), signé et daté : Leroux, 1845 ; c'est-à-dire peu avant sa restauration.

Pour l'intérieur (voir fig. 23), nous avons déjà noté les observations de dom Fonteneau. Lorsque le baptême par immersion fut abandonné, on installa sur l'emplacement de la piscine comblée des fonts pour le rite nouveau, avec un ciborium qui existait d'ailleurs peut-être auparavant, et dom Fonteneau les décrit ainsi (t. LXXVII, p. 190 et s.) : "Ils consistaient dans une masse de pierres et de marbre presque brut dont l'ensemble formait une espèce d'autel couvert d'un dôme soutenu par quatre piliers. Comme ces fonts masquaient le grand autel et en dérobaient la vue lorsqu'on entrait dans la nef, M. de la Poype, évêque de Poitiers, les fit démolir en 1703 et dégagea aussi cette église de tout ce qu'il y avait d'incommode pour les fidèles ». Bobinet, curé de Buxerolles, dans sa chronique, attribue cette démolition au P. Grignion de Montfort. Il fit démolir, dit-il, " un ancien monument qui était entre quatre piliers, au milieu de l'église, qu'on croit être le lieu où l'on égorgeoit les victimes lorsqu'elle était le temple des faux dieux; ce qui en faisoit voir l'antiquité et devoit pour ce sujet être conservé, selon le sentiment des plus judicieux "n ${ }^{11}$. Le P. de la Croix répara avec du plâtre ces malheureux fonts bartismaux ainsi diffamés par le célèbre missionnaire (on peut les voir fig. 5,6 et 16 ).

A la suite de l'enlèvement du ciborium, comment fut disposé l'édifice?

Des plans conservés aussi à la Bibliothèque de la ville de Poitiers nous donnent quelques renseignements. La disposition intérieure nous montre trois autels, deux latéraux et celui de l'absidiole est précédé d'une colonnade rectangulaire dans la cella. Un petit cercle indique l'emplacement du baptistère ou plutôt du conduit suivi par Siauve, que Baumesnil désigne comme destiné à l'écoulement des eaux. La première vue intérieure nous est sommairement donnée par Caumont dans son cours d'archéologie, édition de 1830. Le plan montre qu'on voyait encore l'amorce de l'absidiole sud qui était ruinée jusqu'aux fondations ; sur l'aspect latéral, elle n'est plus figurée non plus que l'arc de jonction avec la cella. Mais les images les plus précieuses que nous ayons avant les restaurations sont les relevés publiés par Jules Gailhabaud en 1853, mais dessinés vers $1836^{12}$. Ces plans et coupes (fig. 17 et 23 ) sont pour ainsi dire d'une exactitude photographique et dans les parties restées intactes, on retrouve le détail de l'édifice pierre à pierre. A cette époque, le baptistère se compose de la cella rectangulaire, du narthex et de l'absidiole est, que nous connaissons. La fenêtre avait alors été défigurée par un remplage gothique. Gailhabaud indique l'absidiole circulaire du sud comme réduite à ses fondations et son entrée fermée par un mur. Au-dedans, les deux colonnes de l'arc d'introduction restent visibles. De l'absidiole nord, aucune mention : elle était détruite depuis longtemps. L'arc et ses colonnes étaient noyés sous les enduits de l'extérieur et de l'intérieur. La piscine était ouverte depuis les fouilles de Siauve en 1803, mais plus profonde car le sol du monument était surhaussé de $0,91 \mathrm{~m}$. On passait sur un même plan du bas de l'escalier d'accès jusqu'à

(11) Bibliothèque municipale de Poitiers, Ms 347 (142), p. 1432.

(12) Monumenls anciens el modernes, Paris, 1853, 4 vol. 


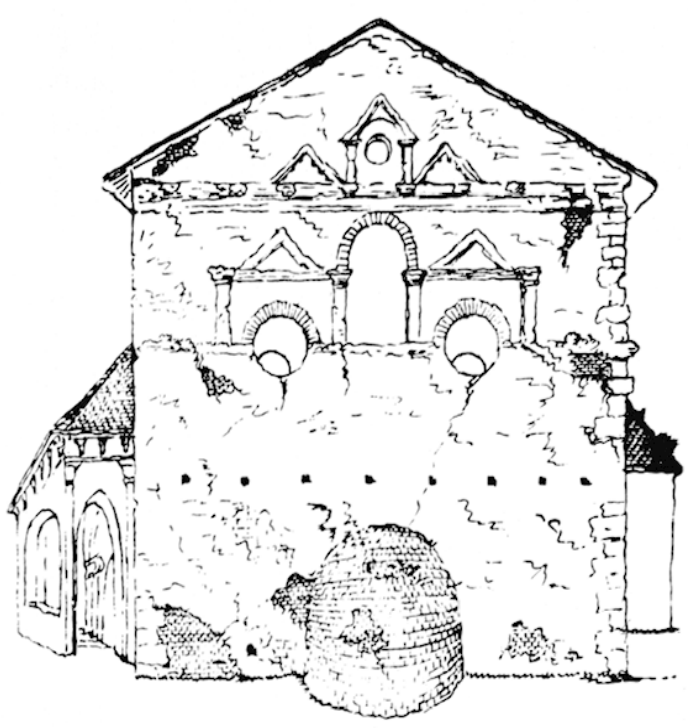

1. -- Le baptistère Saint-Jean vers 1760 , dessin de Beaumesnil, Bibliothèque Municipale de Poitiers. L.a plus ancienne figuration connue du monument. Si le narthex est fort mal représenté, nous y remarquons l'absidiole disparue vers 1820 . Cette photo et celles qui accompagnent l'article ont été prises par F. Eygun.

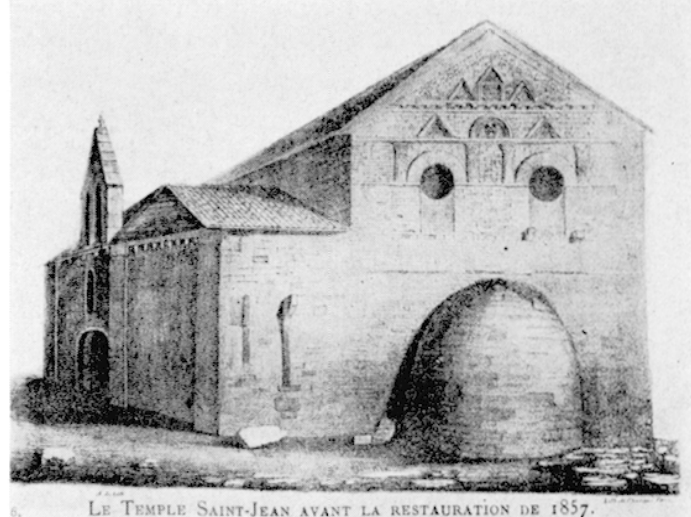

2. - Le baptistère Saint-Jean vers 1820 , vu par le lithographe Chalopin, de Caen. L'absidiole sud est encore en place.

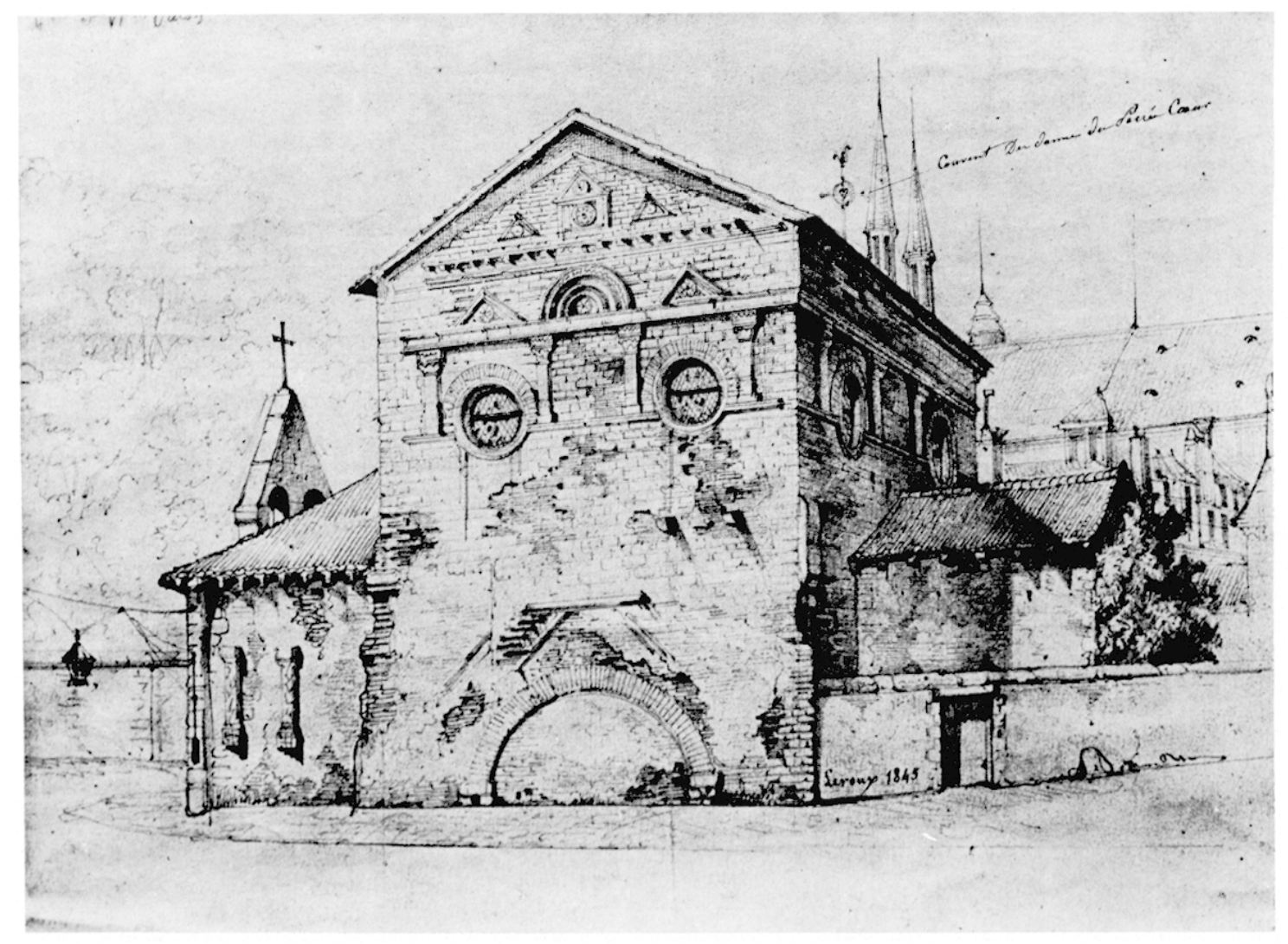

3. -... Aspect du baptistère còté sud en 1845, quelques années avant la restauration. Ce dessin semble noter la trace d'une toiture qui aurait existé au-dessus du cul de four disparu à cette date. Dessin du Ylusée de Chàtellerault, signné Leroux, 18.5. 
l'entrée de l'absidiole est, surélevée seulement d'une marche. De la sorte, les bases des colonnes de la cella étaient cachées. Les chapiteaux paraissent avoir été très empâtés par des enduits. Un arc d'une petite porte ou arc de décharge à claveaux assez larges dans la muraille est, à gauche sur le plat du mur, était masqué partiellement par la colonne qui reçoit l'extrémité de l'arcature vers l'angle $\mathrm{n}$.-e. de la cella. La restauration de .Joly-Leterme a fait disparaitre cet indice, de facture probablement assez tardive.

Malgré le comblement du centre, le pavage restait très au-dessous du sol extérieur. Il suffira de dire que le sommet des claveaux apparents de l'absidiole sud était de $2,85 \mathrm{~m}$ au-dessus de la rue en dehors de l'édifice, et à $4,48 \mathrm{~m}$ à l'intérieur, soit une dénivellation de $1,63 \mathrm{~m}$, ce qui était encore beaucoup moins qu'actuellement où elle atteint environ $4 \mathrm{~m}$ - et il faut maintenant 22 marches pour aller de l'extérieur à la margelle de la piscine. Cet encaissement, qui est avec d'autres proportions celui de la cathédrale, déjà surélevée, à sa reconstruction de 1018 , de $1,50 \mathrm{~m}$ par rapport au sol de l'église mérovingienne, peut s'expliquer par l'abandon de l'entretien et l'effondrement des terrasses qui s'échelonnaient sur les pentes de la ville romaine et dont plusieurs étages ont été reconnus. De plus, à diverses reprises, l'Échevinage puis la voirie ont surélevé le sol pour l'entretien des chemins, notamment en 1703 et 1792.

Tel était donc l'aspect général du monument au moment où sa restauration va être décidée, en 1855 : il se compose de la cella centrale rectangulaire, de l'absidiole est légèrement en trapèze à l'extérieur, à 5 côtés vers l'intérieur, dont la fenêtre a été refaite au xve siècle ; enfin du narthex à cinq côtés par lequel on entre. Le sol est surélevé par rapport au niveau primitif. La piscine, retrouvée en 1803, est très enfouie. Les absidioles latérales n'existent plus. Les colonnes et les chapiteaux sont empâtés par les crépissages. Les fresques des parties hautes subsistent en majorité, mais cachées sous les badigeons.

\section{Les reslaurations de 1855 .}

Les comparaisons entre les relevés de Gailhabaud et ceux de Joly-Leterme sont très suggestives. Le premier était un architecte doublé d'un archéologue attentif ; le second n'était qu'architecte. Ses plans, ses rapports et ses travaux le prouvent abondamment, malgré sa bonne volonté qui ne saurait être mise en doute. Sa restauration a cependant été plus fidèle qu'on ne le croyait et la plupart du temps, à l'extérieur, il a remplacé les appareils usés par des éléments de dimensions identiques. Cependant, certaines réfections, comme celles du mur sud de l'absidiole principale, de celui de l'est à l'intérieur n'ont pas laissé subsister grand chose de l'état antérieur. Son rapport du 31 décembre 1855 indique d'ailleurs la difficulté du travail : "le monument fut maintenu au-dessus du sol par un carrelage en bois et fer, étaiement solide, mais peu dispendieux, les parties inférieures reprises et consolidées et la base que nous avions trouvée minée, poussée, bouchée par la vétusté, l'incendie et les infiltrations, la surcharge de $4 \mathrm{~m}$ de remblais (à l'extérieur), par mille causes incessantes de ruine, fut reconstruite en sous-œuvre, sous les murs ébranlés, de manière à résister longtemps désormais aux causes ordinaires de destruction des monuments. " En même temps, il fallut retrouver le sol primitif, recouvert par 0,91 m de remblais divers qui masquaient les bases et unifiaient les niveaux anciens entre les divers membres de l'édifice.

Consolider, rendre à Saint-Jean ses proportions réelles, eût été excellent, mais JolyLeterme a construit de toutes pièces les absidioles latérales qui n'ont plus aucun rapport 
avec celles que nous montraient les dessins anciens. Il les a même couvertes d'une sorte de dôme à ressauts qu'il a fallu enlever récemment pour le remplacer par une couverture de tuiles plus décente et plus harmonieuse (mais qui ne rappelle pas plus l'état antérieur à 1830). Il a renouvclé trop de claveaux, retaillé quelques chapiteaux dans l'absidiole est et, après avoir retrouvé des traces du sol mérovingien orné de quelques vestiges de mosaïques (fig. 4), fait disparaître ceux-ci afin d'avoir la profondeur nécessaire pour loger un béton recouvert de carrelage de briques.

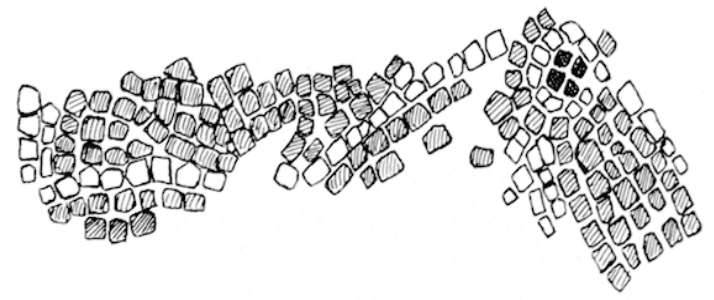
4. - Fragment de mosaïques calquées sur un relevé de
la bibliothèqu municipale de Poitiers. Ln croquis de
Joly-Leterme dans le dossier du baptistère aux archives
des Monuments historiques a Paris indique sommairement
quil s'agissait de croix inscrites dans un cercle et dessinces
au compas, l'intervalle des bras dessinant ainsi quatre
pètales de marguerites. Le musée de l'F́chevinage conserve
quelques smalts de ce pavage.

Tout cela rend fort difficile aujourd'hui la lecture du baptistère.

Les recherches du P. de la Croix. - Lorsque le $\mathrm{P}$. de la Croix étudia le monument à son tour, de 1890 à 1897 , il put pratiquer à l'extéricur des fouilles importantes et établit dans l'édifice des échafaudages pour examiner les murs, mais il n'entreprit pas de sondages à l'intérieur et se contenta, à ce sujet, de mentionner les recherches de Siauve et de JolyLeterme en négligeant, ici ct là, des détails importants. C'est ce que n'a pas compris E. Ginot, qui affirme que "grâce à dix années de fouilles méthodiques descendues jusqu'au sol vierge, tant à l'extérieur qu'à l'intérieur de l'édifice, il put dresser le plan primitif ». Ses fouilles à l'extérieur lui firent rencontrer de nombreuses substructions gallo-romaines qu'il prit pour des annexes du baptistère (en blanc sur la planche VIII, plan I). Trompé par les relations préalables, il affirme (p. 26 de son étude) " $Q u e$ les nombreuses fouilles pratiquées dans les terrains intérieurs et extérieurs du monument n'ont révélé aucune fondation autre que les fondations de notre édifice. Il est donc impossible de considérer les matériaux qui le composent comme ayant appartenu à une construction antérieure ". Étonné cependant par leur hétérogénéité, il en concluait que ceux-ci « avaient appartenu à des édifices plus anciens, abandonnés ou détruits ". C'est pourquoi il a cherché à expliquer par des raisons diverses et peu concluantes les salles incohérentes qu'il avait découvertes autour du bâtiment.

Au contraire, en effet, de ses assertions, le sous-sol du baptistère est, nous le verrons, encombré de substructions du II ${ }^{\mathbf{e}}$ ou III $^{\mathbf{e}}$ siècle arasées, que ni Siauve, ni Joly-Leterme n'ont remarquées, ce qui prouve que leurs sondages ont été très localisés. L'interprétation donnée par le P. de la Ćroix du monument, aussi bien dans son plan que dans son élévation, devait donc être faussée par ces erreurs de base. C'est ainsi qu'il a cru primitives les ouvertures donnant sur les absidioles et qu'elles pouvaient s'ouvrir sur des salles en fait déjà détruites lors de la construction du baptistère et sans rapports avec lui. Ses affirmations sont d'ailleurs rarement accompagnées des raisons d'être et des preuves qu'on aimerait voir suivre. Il a conclu ainsi que l'arcature du mur est et ses chapiteaux étaient antiques, comme tous les autres, que la cella n'avait pas de fenêtres à l'origine et que la charpente 


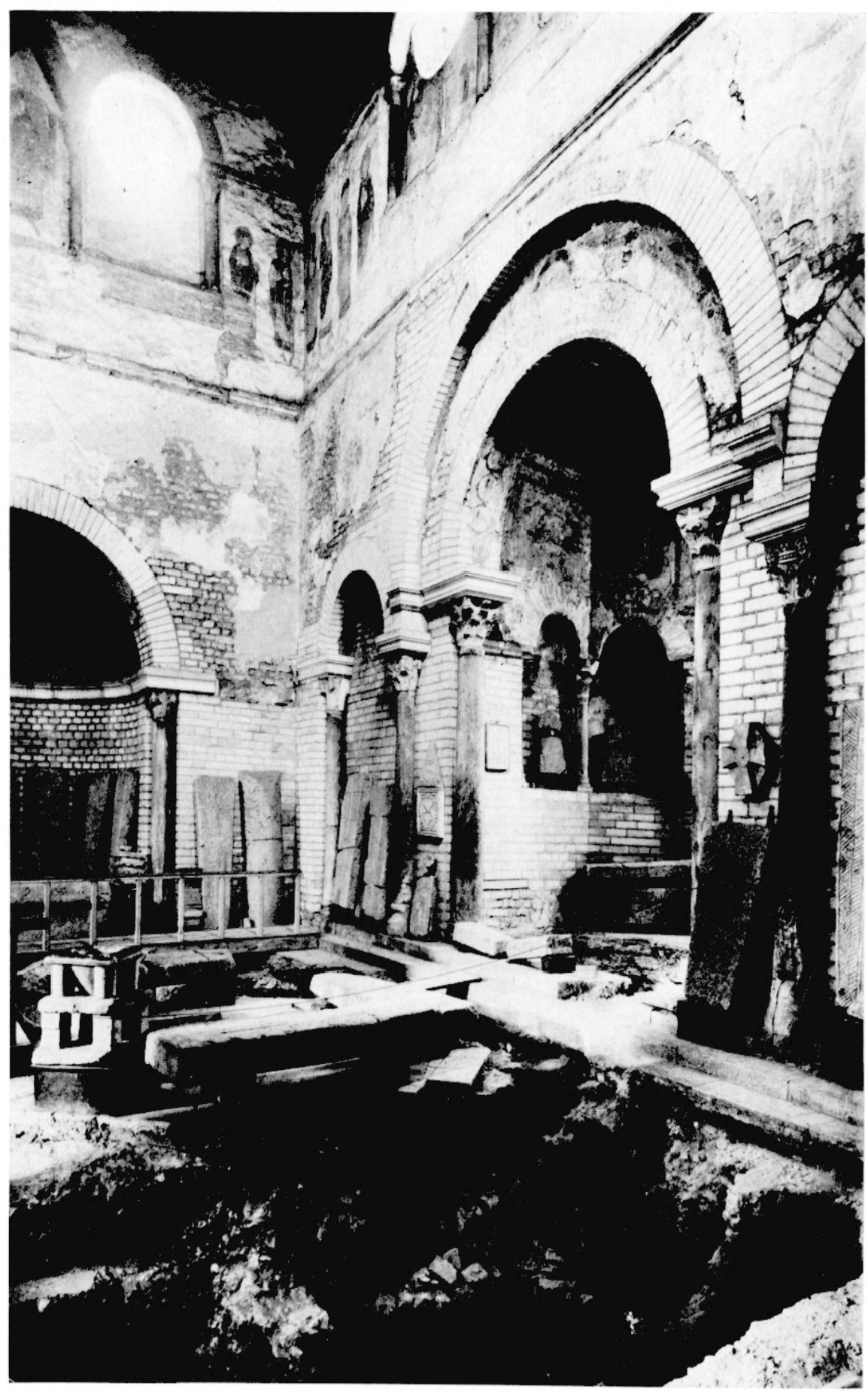

5. - Vue intérieure du baptistère et des fouilles, prise de l'absidiole sud vers l'angle n.-e. L'arcature de la face orientale est plaquée sur le mur précédent.

était inversée à 90 degrés, tout cela sans l'ombre d'une démonstration. Certes, les observations des auteurs qui ont étudié le baptistère doivent être considérées avec soin. Elles nous apportent sur bien des points des remarques excellentes. Nous les utiliserons constamment mais, à l'aide de faits révélés par les fouilles, nous devons parfois leur donner une interprétation nouvelle. 


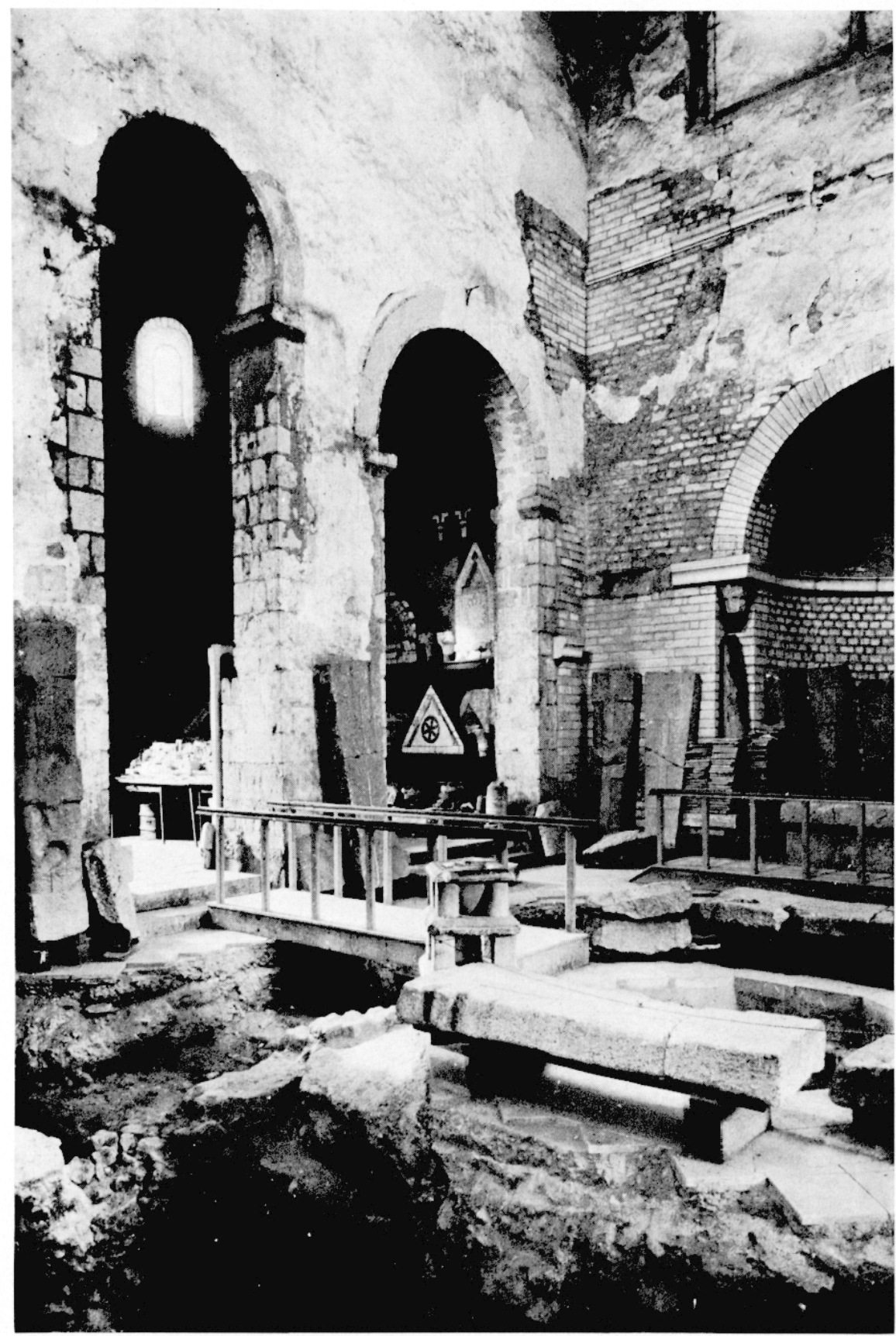

6. - Vue prise du même point, mais vers l'angle n.-o. de la cella baptismale. Les ouvertures d'accès du "narthex" sont de la fin de la période carolingienne, époque oú trois arcs remplacèrent les deux portes primitives.

\section{RÉsultats DEs Folilles de $1958-60$}

Les fouilles ont été ouvertes le jeudi 12) juin 19:38. Nous n'avions d'abord pensé qu'à creuser une tranchée allant de la piscine jusqu'au fond de l'absidiole pour savoir si la fameuse couche de béton gris blanc signalée par Joly-Leterme s'étendait bien à travers tout l'édifice et faisait corps, ainsi qu'il le disait, avec la piscine. Cela eût établi la contemporanéité de l'absidiole mérovingienne et de la piscine, comme l'avait pensé M. Jean 


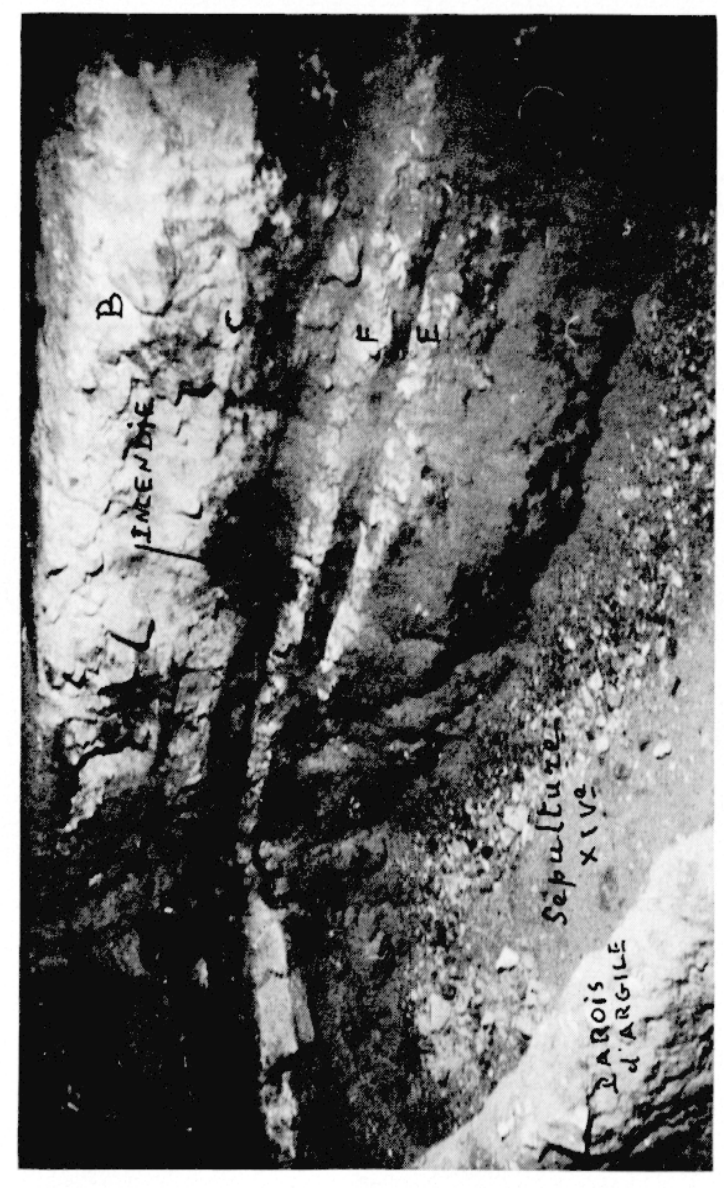

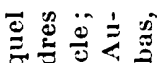

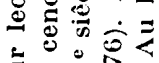

के

Е

용ㅇㅇ

点。

造

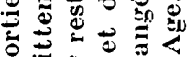
9 है

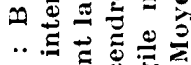
สี 要 बิ

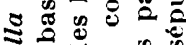
过

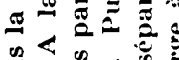
政

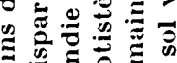
范热

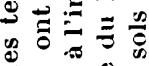
o $\overrightarrow{0}$

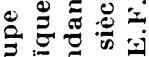
8 骂 190

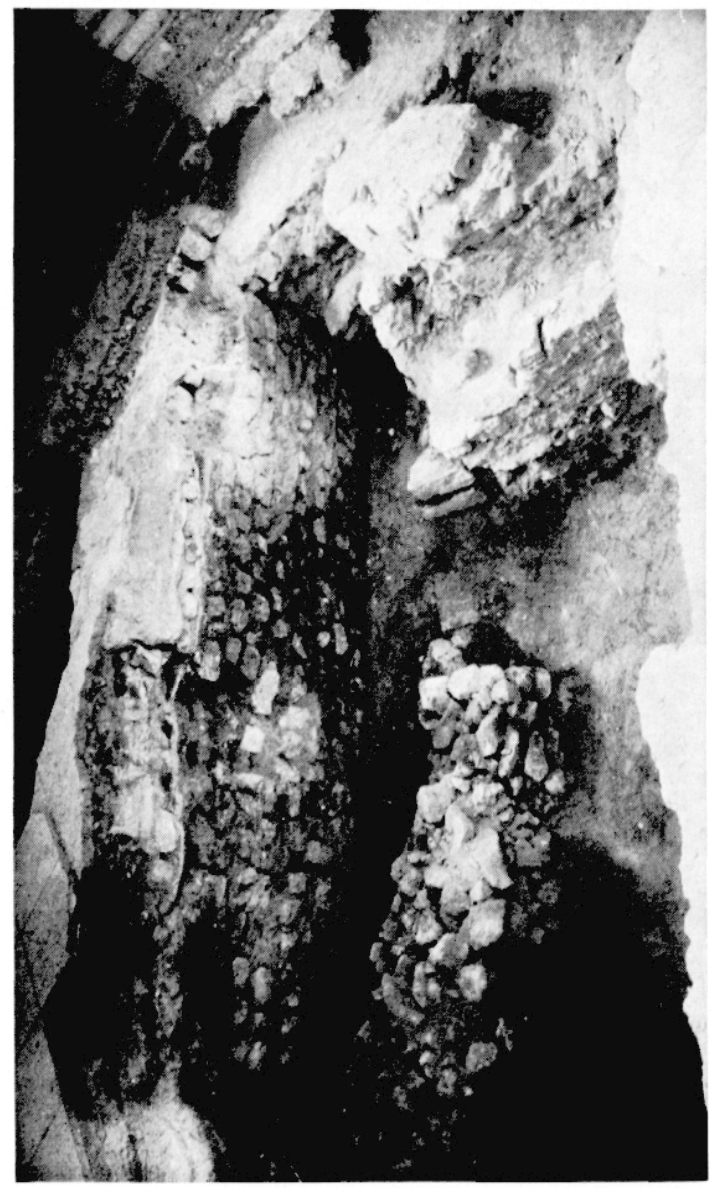

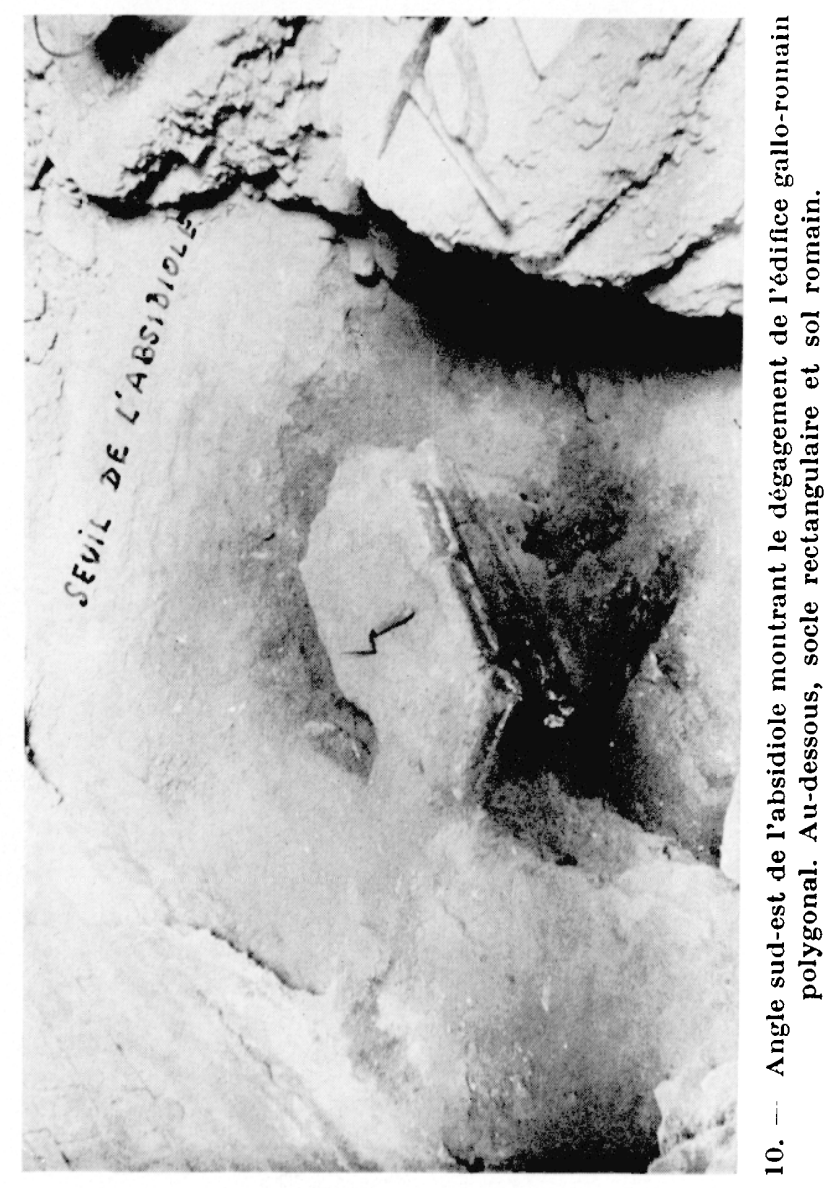

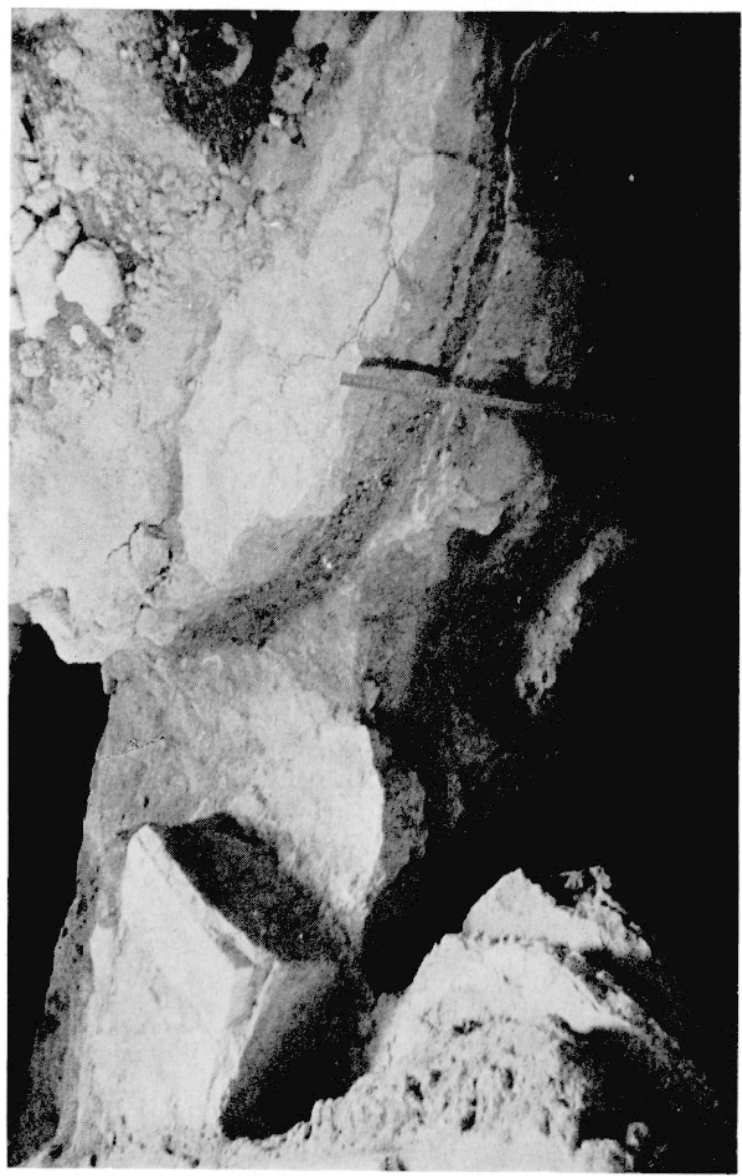


Hubert sur l'énoncé du rapport de cet architecte. Nous fùmes vite fixé. Le béton friable et tendre qui avait été étendu lors de la restauration mérovingienne sur l'ensemble de l'édifice pour recevoir les mosaïques joignait bien la piscine mais n'était pas lié avec elle et n'avait aucun rapport avec le béton rose antique et inattaquable dont elle était faite. Puis d'autres substructions apparaissaient : il fallait continuer les recherches. Voici donc l'exposé général des résultats (fig. 5 et 6 ).

A) Absidiole et salle baplismale. - Le sol du baptistère a été exploré en partant de l'absidiole est, mérovingienne, puis petit à petit, nous avons dégagé la cella et vidé la majeure parties de ces deux salles.

$1^{0}$ Tout d'abord il a fallu soulever le carrelage de briques installé en 1865 par JolyLeterme avec l'épaisseur de mortier rose et de béton destinés à le recevoir. Cet ensemble moderne s'étendait uniformément sur une profondeur moyenne de $0,35 \mathrm{~m}$;

$2^{\circ} \mathrm{Au}$-dessous, nous avons aussitôt retrouvé (en B sur les coupes) ce que cet architecte appelait un béton gris blanc et sur lequel il signalait de place en place des mosaïques que nous avions espéré remettre au jour. Nous avons malheureusement constaté que pour rattraper avec son carrelage le niveau ancien du baptistère, il avait arasé toute la surface de cette couche dont ne subsistait plus par endroits que la partie inférieure sur $0,20 \mathrm{~m}$ d'épaisseur. Les mosaïques n'existaient donc plus partout où elles avaient été signalées sur son plan. Ce béton friable et peu consistant avait dû s'étendre à l'ensemble de l'édifice. On le rencontrait ainsi auprès de la piscine et il n'y avait aucun rapport, si ce n'est de contact, entre ce matériau peu solide et le très dur béton rose de celle-ci. Il avait disparu, sur des surfaces beaucoup plus importantes que le plan de Joly-Leterme, publié dans l'ouvrage de Mérimée, ne pourrait le laisser croire, détruit par des inhumations nombreuses et par son nouveau nivellement. Il subsistait, en revanche, en quelques endroits non indiqués sur ce même dessin, par exemple le long du mur sud.

B) Particularités de l'absidiole. - Au-dessous, régnait un peu partout un sol de remblais de profondeur très variable, selon les lieux, la terre vierge étant à $1,50 \mathrm{~m}$ ou $1,75 \mathrm{~m}$ de profondeur du dallage $\mathrm{xIx}^{\mathrm{e}}$ en moyenne; au milieu de ce remplissage se rencontrent des vestiges romains nombreux (fig. 7 et planches 3 à 8). En premier lieu, un mur gallo-romain parementé de petit appareil plus soigné vers l'ouest traverse diamétralement la fouille. Il était déjà connu grâce à ses extrémités extérieures par le P. de la Croix, qui le supposait devoir délimiter une salle annexe du baptistère primitif. Il supporte au milieu un béton qui déborde en encorbellement vers l'est et sert de base à un autel rectangulaire mérovingien (fig. 8). Celui-ci, construit en moellons appareillés, était recouvert d'un épais mortier avec enduit de même apparence que celui de l'hypogée des Dunes. Cet autel, arasé plus tard un peu au-dessus du niveau du béton gris à mosaïques a évidemment été vu par Joly-Leterme, qui l'a noyé dans son sol mais ne l'a pas signalé, n'en ayant pas compris le sens.

Du côté est, le sol sous-jacent au support de l'autel était formé d'une légère couche de remblais $(0,20 \mathrm{~m}$ environ) sur de la terre végétale contenant des tessons de poterie galloromaine sigillée ou rustique. A $0,85 \mathrm{~m}$ de la surface, un sol de béton gallo-romain brisé s'enfonce sous la base de l'absidiole vers l'est. 
Du côté ouest du mur, le remblai formé de moellons et de mortiers détruits livrait aussi des fragments de céramique romaine et de tuiles à rebords, jusqu'au sol vierge mais en le vidant on a retrouvé un mur de pierres sèches, pas tout à fait parallèle au mur appareillé ; puis, à l'angle sud-ouest, les bases d'une maçonnerie soignéc, parementée de petit appareil allongé assis sur un blocage (fig. 10). L'angle seul conservé indique une construction de plan polygonal. Vers l'extérieur, subsistaient les traces d'un sol bétonné situé au même niveau que celui passant sous le mur est de l'absidiole. Vers l'intérieur, qui était revêtu d'un enduit, à $0,70 \mathrm{~m}$ de la surface, un autre blocage pavait cet édifice broyé sous le mur sud de l'absidiole.

C) Particularités de la salle baptismale. - Dans la cella, outre les niveaux précédents, carrelage moderne et son mortier, béton mérovingien gris-blanc à mosaïques disparues (fig. 9), nous trouvons aussitôt au-dessous, là où il a subsisté, un béton rose plus compact, au niveau du blocage de la piscine : c'est l'ancien sol du baptistère au rve siècle. Ce mortier, plus consistant que celui qui le couvre. l'est cependant moins que celui de la piscine. Beaucoup de villas gallo-romaines de l'Ouest possèdent un pavage semblable. Il devait avoir un revêtement disparu. Il mesure en moyenne $0,17 \mathrm{~m}$ d'épaisseur avec un hérisson sous jacent.

Mais cette piscine, quelle est sa structure ? Siauve l'avait bien remarquée avant les démolitions du fabricant de cloches. "On avait employé, dit-il, autant que je puis croire, le mortier que Vitruve désigne sous le nom de signinum, et qu'il conseille pour la confection de citernes. On aperçoit de distance en distance, un rang de ces grandes briques à double rebord que je crois être les laleres pentadoron de Pline ». En effet, les trois marches étaient délimitées par de grandes tuiles à rebords, tegulae noyées dans un ciment très fin de chaux et de brique pilée, bien lissé, vers l'extérieur. Seules subsistent maintenant, intactes et visibles, celles de la marche supérieure puisque les autres ont été brisées par l'artisan qui fondit ses cloches dans la cavité. Mais à la hauteur de celles qui suivent, apparait encore la tranche rouge, brisé au ras du bloc mutilé (voir la coupe, planche V).

Cette construction "d'une dureté extraordinaire ", dit Siauve, qui émousse la pioche, avons-nous constaté, est aussi celle des bases de la cella aux endroits où elles sont dégagées. C'est une maçonnerie de type nettement romain construite par des ouvriers qui sont en possession des meilleures traditions classiques. On ne saurait faire descendre un tel travail plus bas que le $\mathrm{I}^{\mathrm{e}}$ siècle. Sur ce point, le P. de la Ciroix, grand fouilleur de monuments romains, avait bien vu juste. L'enduit lissé qui recouvrait la piscine est formé de deux couches : la première est primitive et il semble que la seconde, où apparaissent des éléments de chaux moins fine, ait été ajoutée lors d'une restauration mérovingienne qui a aussi amené la modification des bords de la piscine, taillés avec un tranchant large.

Le dégagement du bloc de la cuve nous apprenait en même temps comment celle-ci était alimentée et comment l'eau s'évacuait.

Deux orifices au fond avaient déjá été remarqués par Siauve, qui correspondent à des conduits de briques, celui de l'arrivée plus bas que celui de la sortie pour pouvoir maintenir un plan d'eau dans le fond. Mais il n'avait pas été plus loin. A l'extérieur, l'accès du courant était ménagé par un aqueduc de béton de section rectangulaire (voir fig. 11 et 16), couvert par des dalles oblongues 
soigneusement ajustées. Ce conduit se dirige vers l'ouest de l'èdifice, c'est-à-dire vers la portion de l'aqueduc romain, branche provenant du Cimeau dont le tracé assez bien connu est parallèle à la rue Arsène Orillard ${ }^{13}$. Son radier, non comblé, ne contenait que du sable fin en petite épaisseur, ce qui ne semble pas indiquer un usage très prolongé. L'entretien des aqueducs, nécessitant une administration bien ordonnée, n'a guère dû atteindre la fin de l'occupation wisigothe et les conduits que nous connaissons du Haut-Empire se distinguent par un dépòt de calcaire qui n'existe pas ici, en raison d'un emploi de courte durée.

Le départ de l'eau usée, par un tuyau de brique à l'intérieur, aboutissait à une série de tuiles creuses, imbrices, les unes servant de rigoles, les autres préservant les précédentes des terres de remblai (voir fig. 12). L'extrémité de la troisième tuile déversait les eaux usées dans un puits perdu,

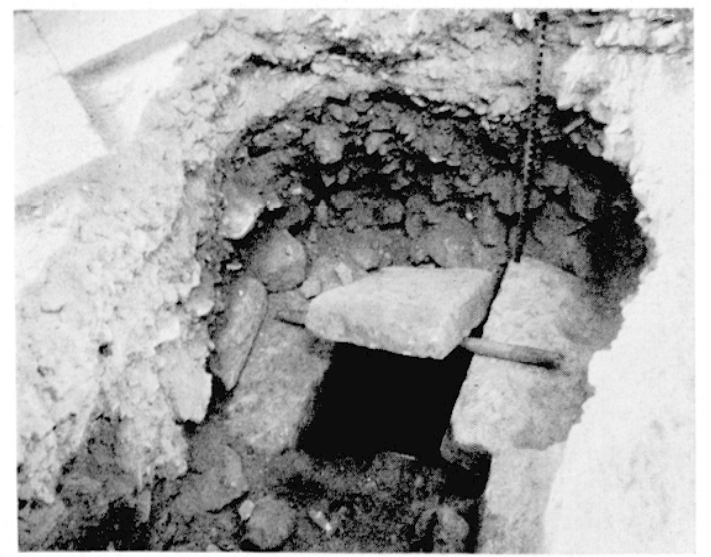

11. - Découverte de l'aqueduc amenant l'eau à la piscine (à droite). Le conduit en béton de forme rectangulaire est recouvert de dalles rectangulaires de calcaire. Un tube de céramique traverse ensuite le blocage.

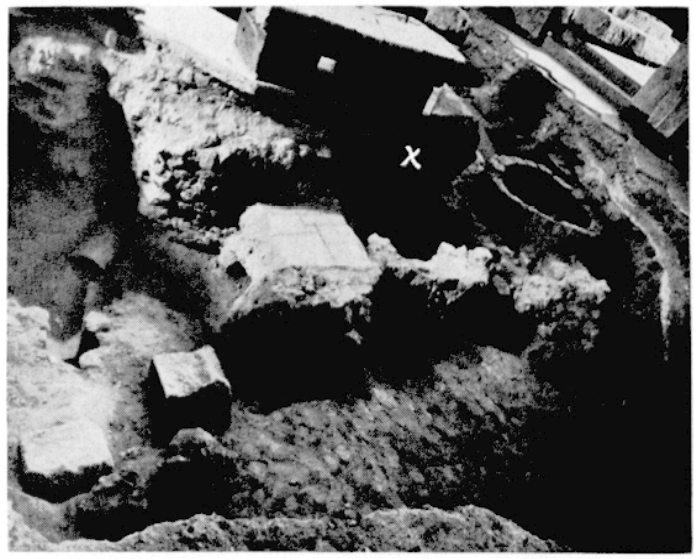

12. - Cella baptismale, côté nord de la fouille montrant le blocage de la piscine cerné de substructions galloromaines ruinées : à gauche, la maçonnerie recouvrant la bouche de chauffage, fig. 14 ; en avant, tuile courbe recouvrant le conduit menant au puisard; au milieu et à droite, vestiges d'habitats détruits, dont un pavage de calcaire fin blanc. A droite, construction d'un fourneau circulaire du début $x_{1} x^{e}$ siècle. En X, maçonnerie de la piscine réparée au $x_{1} x^{e}$ siècle.

maçonné en pierres sèches (fig. 13). En dégarnissant la piscine, nous avons constaté que l'angle n.-o. avait été réparé, soit à la suite des fouilles de Siauve, en 1803, soit plutôt par Joly-Leterme. Le P. de la Croix avait considéré, d'après le premier, que le bloc de béton avait une superficie rectangulaire débordant de trois côtés de $0,40 \mathrm{~m}$ la piscine et de $1,30 \mathrm{~m}$ à l'ouest. En fait, la forme générale du massif est à peu près circulaire vers l'ouest et le sud et s'aplatit des deux autres côtés pour éviter le travail de démolition de murs romains. Le côté ouest a servi de plate-forme à une dalle percée d'un trou surplombant un conduit carré formant entonnoir au début, puis mesurant ensuite $0,182 \mathrm{~m}$ et à 0,542 du sol traversant une nouvelle dalle rectangulaire avant d'aboutir à l'aqueduc dont Siauve ne décrit pas la forme. A mi-hauteur, ce conduit vertical se trouvait obturé par deux têtes de morts. Pour l'étudier, Siauve a démoli, assise par assise, cette curieuse disposition dont nous n'avons plus retrouvé trace mais qu'il a décrite assez minutieusement pour que le $P$. de la Croix ait pu la restituer par le dessin ${ }^{14}$.

(13) Còté ouest. Dans les notes du P. de la Croix aux Archives de la Vienne, Album 53, p. 10, on note que dans cette rue (alors dite du Gervis vert), en face de l'École communale (aujourd'hui Maison du Peuple, c'est-à-dire au no 24 actuel, immeuble acquis par la Mutuelle), se trouvaient l'aqueduc, un bassin et une canalisation. Nous avons retrouvé nous-même la conduite rue Arsène Orillard, parallèle à la rue, dans la cour du n 12 .

(14) Elude sommaire, pl. III. 


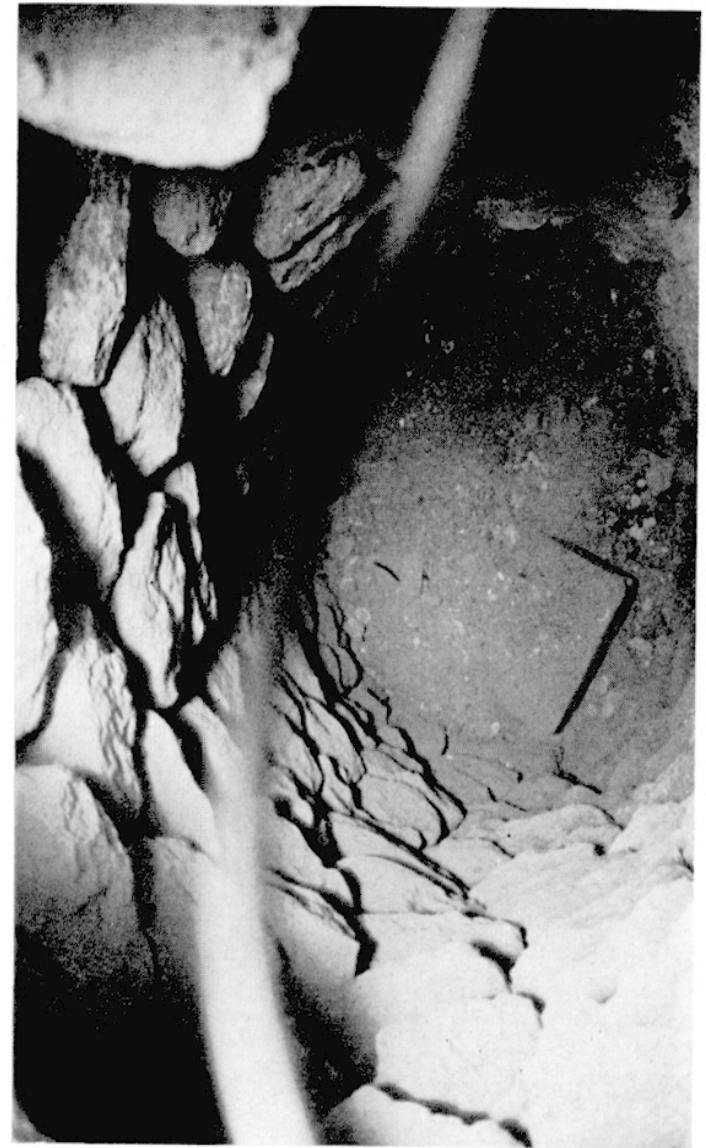

13. - Puisard d'évacuation des eaux usées de la piscine.

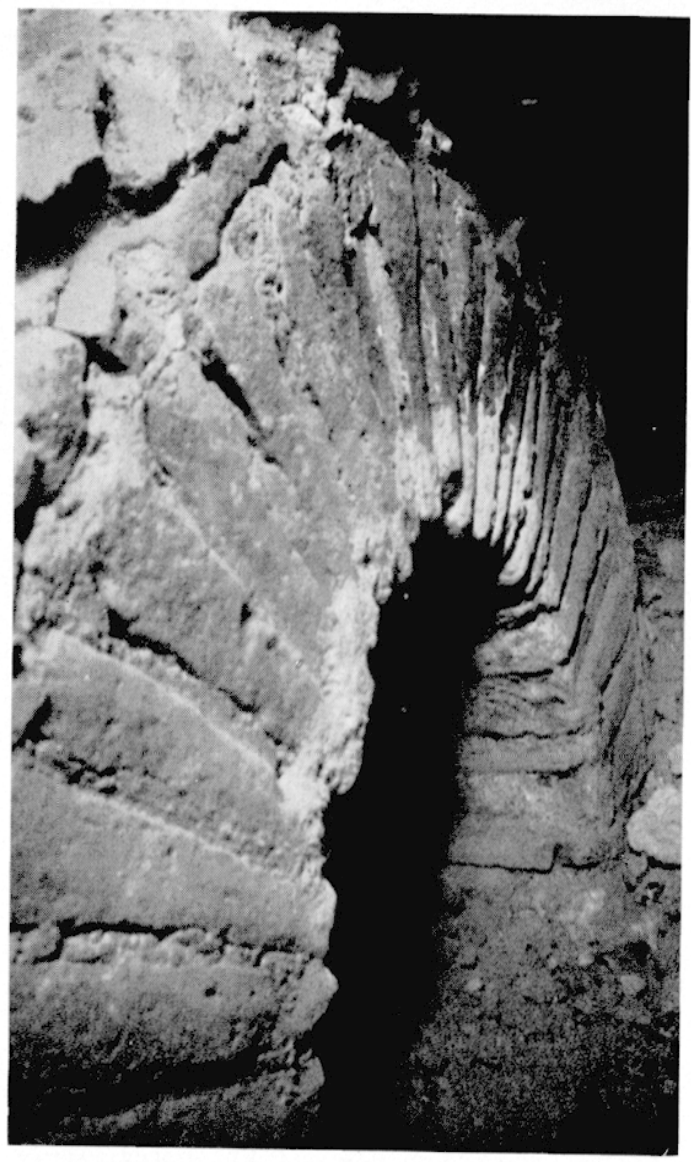

14. -- Entrée de la conduite de chauffage située entre le blocage de la piscine qui l'a coupé, et le seuil de l'absidiole est : dessin planche $V$, en haut, à droite.

Le sol du ive siècle est appuyé soit sur le sommet de constructions du $\mathrm{I}^{\mathrm{er}}$ au III $^{\mathrm{e}}$ siècle arasées, soit sur des remblais, là où aucune substruction ne s'interpose et où ils n'ont pas été remaniés par les inhumations du Moyen Age. On y remarque plusieurs couches : sous le béton du baptistère apparaît une épaisseur de gravats terreux de 12 à 15 centimètres reposant sur une mince stratification noire de cendres et charbons avec poteries diverses de 0,02 à 0,04 , lit au-dessous duquel se voit une aire de béton gallo-romain $(0,06 \mathrm{~cm})$ rougie par le feu, sans doute le lugubre souvenir de l'invasion de 276 . Encore $\overline{\mathrm{cm}}$ de sol argileux et, à nouveau, un béton gallo-romain sur d'autres remblais pour atteindre la terre vierge, à $1,65 \mathrm{~m}$ environ du carrelage moderne.

Tous ces décombres sont là encore, comme dans l'absidiole, délimités par endroits, par des constructions romaines éparses que nous allons énumérer, sans prétendre déterminer leur plan primitif, tant clles ont été détruites.

Tout d'abord à l'est, entre la piscine et le mur de la cella qui sépare de l'absidiole, se rencontre l'entrée d'un foyer d'hypocauste (fig. 14) remarquablement construit d'un arc en plein cintre dont les éléments en terre cuite formant claveaux en trapèze étaient enduits sous le berceau d'un crépi rose et extradossés de deux rangées de briques incurvées, le tout assemblé par un excellent mortier rose. Seule la photographie à la lumière artificielle nous a permis de prendre connaissance de cet 


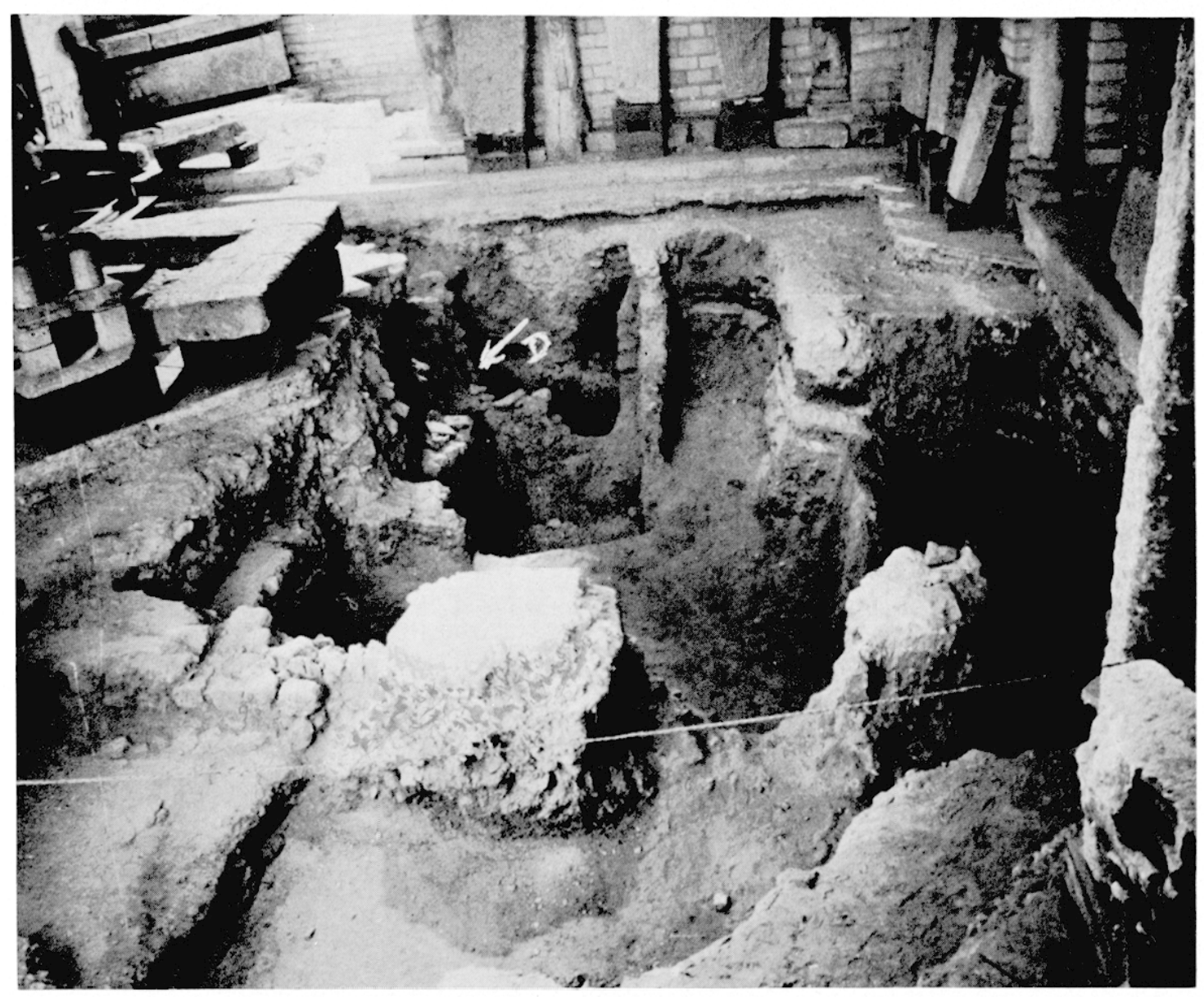

15. - Vue des fouilles, còté sud de la piscine, prise de l'arcade sud d'entrée du narthex vers l'est. Au premier plan, mur gallo-romain coupé par des sépultures du Haut Moyen Age dont les alvéoles maçonnés d'argile se voient au fond, coupant les couches du terrain photographićes fig. 10. En D, dépotoir romain.

ensemble, qu'il a fallu examiner à tâtons, l'espace entre la muraille qui fait face et la tranche de l'ouverture ne laissant pas passer la tête.

Une aire de béton gris romain lui sert de base et vers le sud un blocage, comme les éléments précédents, a été coupé par l'établissement de la piscine. Il délimite d'un côté un dépotoir, fermé de deux autres côtés par des murailles soigneusement construites. Des ossements, des clous, des poteries diverses, noires et fines, quelques rares fragments décorés à la roulette, des terres grossières en ont été retirées. D'autres sigillées portaient les noms des ateliers : Aculus, potier de Montans, qui travaillait sous Tibère et Néron, et dont d'autres exemplaires ont été déjà trouvés à Poitiers, Cinnamus, potier de Lezoux, de Trajan à Antonin, Juslus, de Lezoux, rencontré lui aussi à Poitiers, dont l'officine florissait d'Hadrien à Antonin.

Brisées pour l'établissement de la piscine disparaissent au sud des substructions diverses (fig. 15) : une aire circulaire de moellons maçonnés, une muraille nord-sud, détruite de ce dernier côté par des sépultures, au nord un grand dallage de calcaire fin soigneusement appareillé, borné par une muraille très détruite et sous laquelle passe un conduit.

A l'ouest, enfin, une longue muraille de moellons appareillés sur les faces traverse à peu près complètement du sud au nord la cella (fig. 16). Elle coupe perpendiculairement un autre mur, déterminant des salles où des sols bétonnés indiquent l'existence d'appartements antiques à environ $0,75 \mathrm{~m}$ sous le niveau actuel. Bref, un sous-sol qui fut avant 276 un sol très habité. 
Or, le P. de la Croix est parti sur cette idée que le baptistère avait été construit sur un sol vierge. "Siauve en 1803, dit-il, et les architectes des Monuments historiques en 1852, ont bouleversé l'intérieur du monument ; le premier pour savoir à quel usage il était jadis destiné ; et les seconds pour enlever les morts qu'on y avait enterrés avant d'y établir un dallage et ils n'ont trouvé aucune trace de fondations de constructions antérieures; j'ajouterai qu'au cours des importantes fouilles que j'ai moi-même pratiquées en 189气̆, en 1900 et en 1902, tout autour de l'édifice, je n'ai rencontré aucune trace de constructions ou même de fondations autres que les constructions primitives ". Il n'y a qu'un malheur, c'est que le sol du baptistère est encombré de vestigè gallo-romains et les nombreux squelettes retirés par Joly-Leterme étaient enfouis dans les $91 \mathrm{~cm}$ de surélévation du sol de la cella. Il en restait beaucoup d'autres au-dessous, qu'il n'a pas vus. Un crucifix de bronze doré et gravé, du xve siècle a été retrouvé à côté de l'un des défunts. Le Père a donc cru que toute substruction voisine ne pouvait être qu'une dépendance du baptistère, alors qu'il s'agit seulement des vestiges du Poitiers détruit en 276. Et la carrière qui passe sous la rue et s'ouvre sous l'actuelle abbaye de Sainte-Croix, comme l'escalier qui, du côté du baptistère montait vers le sol, sont des annexes des bâtiments gallo-romains qui n'étaient même plus connues au Iv e siècle, sans quoi on n'eût pas appuyé l'angle de la cella sur une poche vide.

Enfin, au nord-ouest de la piscine, une sorte de four circulaire en briques qui n'est pas antérieur au XIX ${ }^{e}$ siècle est appuyé sur un massif romain. Le fond était garni d'argile et le tout a chauffé. Le sommet était à environ $0,30 \mathrm{~m}$ du carrelage moderne. Ce dispositif était situé au-dessus de caniveaux bouchés avant sa découverte. On sait qu'au début du xIx ${ }^{e}$ siècle, le baptistère a été successivernent occupé par des fondeurs de cloches et des fourneaux économiques. Ce four rustique est le vestige de l'une de ces occupations.

Les murs de la cella dans leur partie inférieure, selon Siauve, le P. de la Ciroix et d'après nos examens, sont construits avec un mortier et des matériaux contemporains de la piscine, ce qui est d'ailleurs logique, celle-ci ayant nécessité l'existence d'une salle pour la contenir. Les substructions en outre indiquent bien la présence d'une salle identique à la cella vers l'ouest, formant sans doute narthex et la présence de deux petites secretaria encadrant l'entrée de l'ouest. D'après les observations du P. de la Croix - et la disposition reste visible dans le fossé - ces secrelaria étaient ouvertes de deux côtés : à l'extérieur à l'ouest, et vers l'intérieur dans le couloir compris entre elles. En revanche, aucune fondation cohérente et contemporaine ne correspondait aux ouvertures des absidioles actuelles. Il n'existait alors aucune porte dans la cella donnant directement vers l'extérieur. Ses trois murs étaient pleins.

Tel était donc le plan du baptistère à l'origine (planche VIII, plan I tracé en noir) : deux pièces rectangulaires identiques précédées de deux secretaria de chaque côté de l'entrée. et pas d'annexes compliquées autour. Seule la salle baptismale subsiste de cette époque mais très modifiée par les adjonctions mérovingiennes. Ce plan est simple et logique. L'éclairage pouvait se faire par des ouvertures pratiquées là où s'ouvrent maintenant les absidioles ou plus probablement par les fenêtres actuelles, qui ont été restaurées par la suite. 

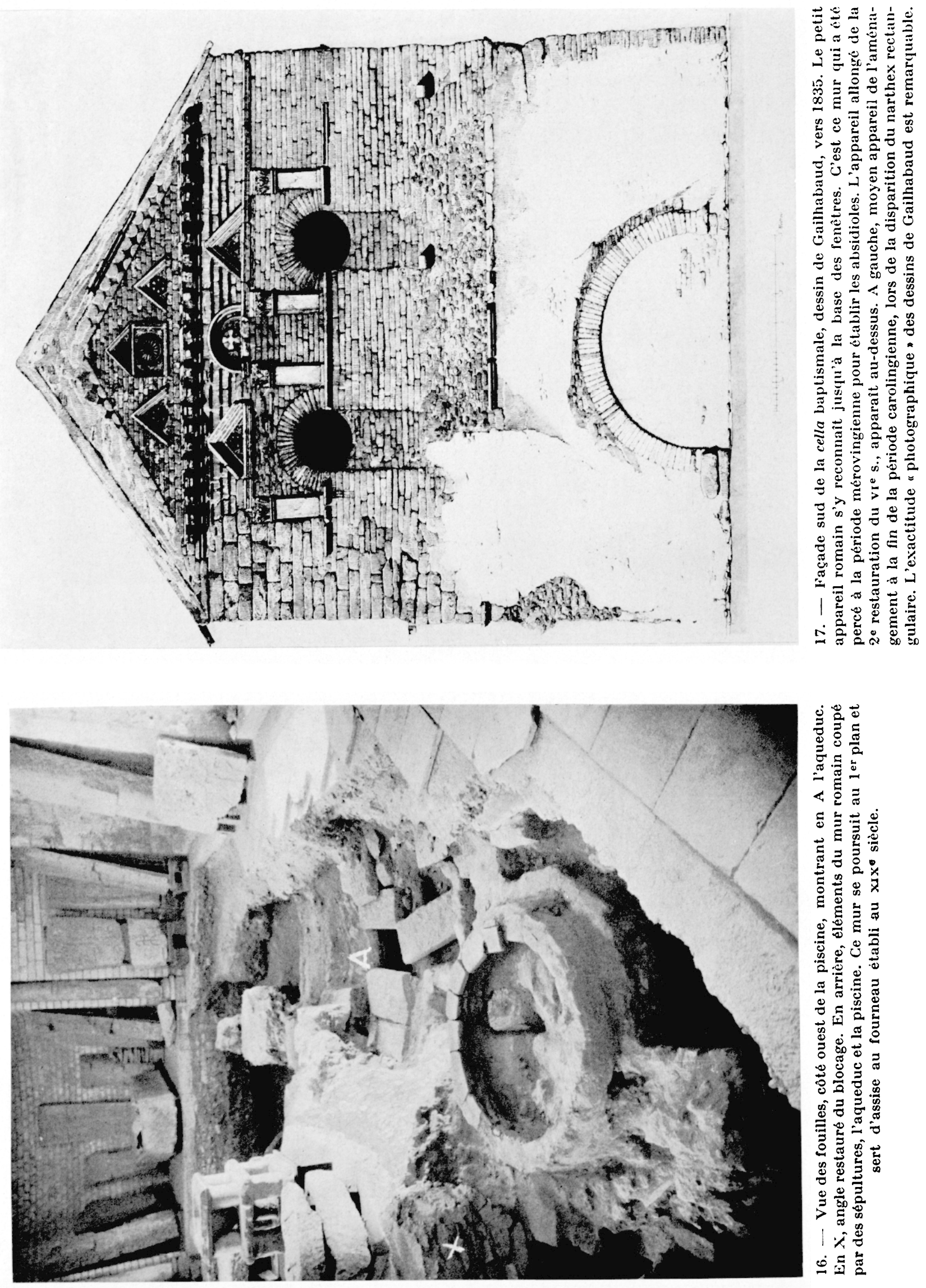

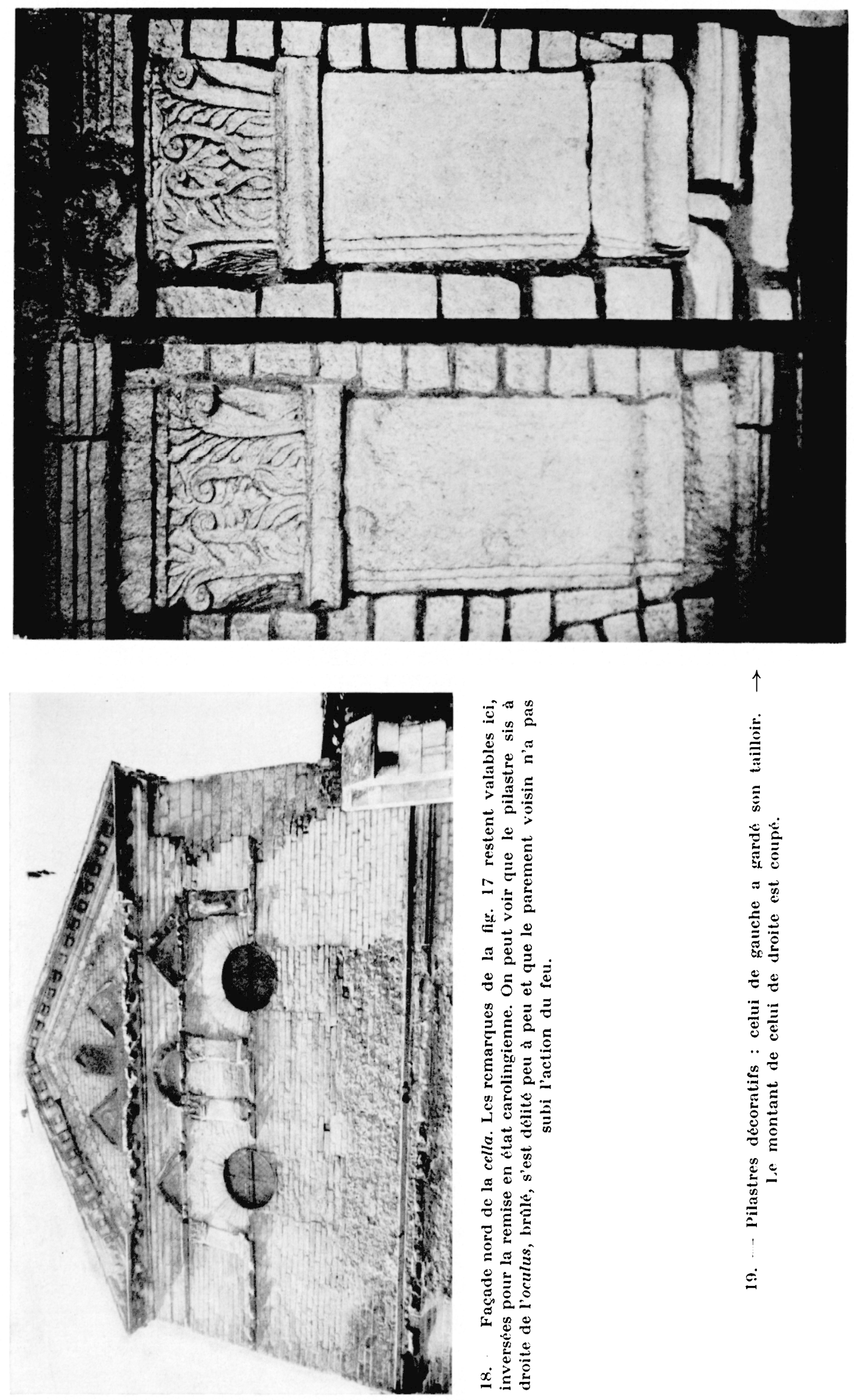

$\uparrow$

萻

苞

$\stackrel{\oplus}{\tau}$

㤩

电

总

$\stackrel{5}{5}$

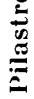

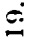




\section{Étude des parties haltes}

A. Slructure et Restaurations. - Une question beaucoup plus délicate est de délimiter la hauteur des murs du Ive siècle (fig. 17). Tout d'abord, les trois surfaces des murailles restées valables sont coupées par deux corniches de profil analogue, que nous retrouvons à l'intérieur. Elles sont composées d'une plate-bande, un filet et une doucine, type très classique. La plus basse court à environ $1,20 \mathrm{~m}$ sous la base primitive des fenêtres, la plus haute continue les impostes de celles-ci. Toutes deux sont d'origine, mais entre elles une partie du parement a été rénovée partiellement. Les côtés intacts de la cella ont été repris au point que la lecture des diverses campagnes y est très difficile car leurs traces se cherauchent ici et là. Essayons d'en déterminer d'abord les faces extérieures moins cachées par les fresques.

Nous constatons, à partir des fondations et sur une hauteur qui va jusqu'à la base des fenêtres (fig. 18), la présence du petit appareil gallo-romain ${ }^{15}$ très abîmé du premier état ; puis au-dessus et par places, aux angles et aux endroits qui avaient besoin de réparations, un parement soigné dont les moellons mieux conservés sont de même hauteur mais allongés. Au-dessus de la corniche sise à hauteur des impostes les cintres des ouvertures sont encadrés par des pilastres décoratifs (fig. 19) limités vers le sommet par une nouvelle moulure en escalier sur un parement d'élément barlongs. Enfin, compris entre celle-ci et les corniches à modillons qui délimitaient la toiture et la base des frontons, se distingue un large bandeau appareillé où les moellons taillés alternent avec les arases de briques (fig. 20). Ciette zone de maçonnerie est en léger retrait sur le mur inféricur. Ses éléments sont cubiques et irréguliers au mur est, soignés et allongés sous les pignons. Au sud, la hauteur de cette zone diminue de l'est à l'ouest comme pour rattraper un tassement. Des restaurations y ont été effectuées, notamment à l'angle sud-est avec l'appareil allongé de la partie médiane qui est donc plus récent. Par ailleurs, l'absidiole centrale qui appartient sans aucun doute à cette première restauration est construite, elle aussi, en petit appareil court. La stèle décorative de son pignon est de même style que celles des côtés nord et sud (fig. 21 ).

Tout cela nous indique : $1^{0}$ une partie gallo-romaine d'origine, jusqu'aux ouvertures; 20 une surélévation ou une reconstruction, totale à partir de la corniche en escalier dans laquelle ont été insérés les éléments décoratifs que nous détaillerons; $3^{\circ}$ à la suite d'un cataclysme, incendie probablement, dont nous constatons les traces sur certains pilastres, restauration avec l'appareil allongé.

La corniche en escalier avec le mur en retrait suppose un parti pris nouveau. On s'est demandé si les éléments décoratifs qui sont enchâssés sur les parties hautes du baptistère sont empruntés à d'autres monuments ou s'ils sont en place. C'est une question impossible à trancher formellement. Ciependant, nous inclinons à penser qu'ils ont appartenu à la première période de restauration de Saint-Jean mais qu'après une catastrophe, il ait fallu, soit pour les dégager, soit pour les replacer, dans les nouveaux parements, les mutiler plus ou moins. En effet, l'incendie est décelable aisément au nord et à l'est sur la face de certains

(15) Le P. de la Croix, et on peut l'en croire, aflirme que ce petit appareil provient de batiments détruits et que sur ces remplois apparaissent des collages des mortiers primitifs Elude sommaire, p. 25). 


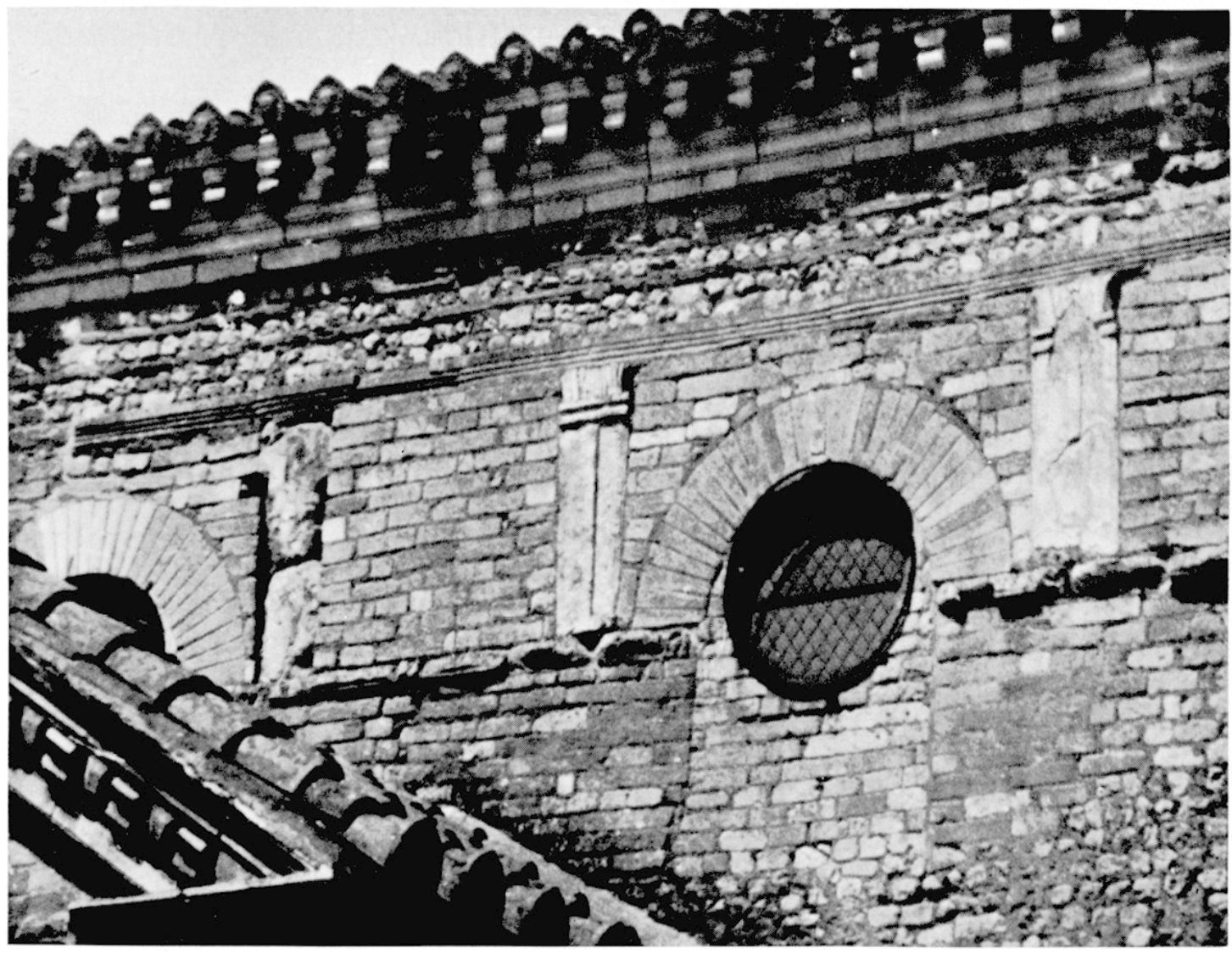

20. -- Détail du còté est, au-dessus de l'absidiole. Ces pilastres, portent une arête ; leurs chapiteaux, dont les tailloirs ont disparu, sont coupés pour les adapter à leur nouvelle fonction. Ceux de droite et de gauche ont subi l'action du feu mais non le parement qui les encadre et appartient donc à une restauration légérement postérieure. La bandeau à arases de briques est formé d'éléments très irréguliers remployés.

pilastres, les encadrements des frontons décoratifs de l'étage à arases de briques et peut-être les modillons à la base du pignon. La pierre calcaire s'est déshydratée à la chaleur et, par la suite, s'est écaillée. A l'intéricur également le P. de la Croix avait remarqué la trace du feu sur les colonnes et les chapiteaux ${ }^{16}$. Cette action du feu a eu lieu avant la restauration faite à l'aide de l'appareil allongé car ses moellons n'ont pas été touchés. Leurs arêtes sont restées vives et les pilastres brûlés ont maintenant l'apparence d'être en retrait sur le niveau du mur, leur surface écaillée étant tombée (voir fig. 18 et 20). Il est probable que c'est à ce moment que durent être réaménagés et partiellement refaits les parements et les pignons, ceux-ci d'une remarquable unité de construction (fig. 22). Cette surélévation nécessita des travaux de consolidation. A l'intérieur, les murs sont doublés et à l'extérieur, étayés par les curicux contreforts situés aux angles. Cieux-ci furent restaurés par JolyLeterme, vivement critiqué à Paris pour ces murailles insolites. Soutenu par les archéo-

(16) Elude sommaire, p. 68. Mais le P. de la Croix date cet incendie de 1018, ce qui est trop tardif pour expliquer les traces visibles à l'extérieur et leur restauration qui ne peut ètre romane. Les marbres restent fragiles. Le dauphin de l'un des chapiteaux, à droite de l'entrée de l'absidiole est, s'est ainsi détaché depuis qu'a été prise sa photographie publice par . $^{\text {lle }}$ Fossard. 


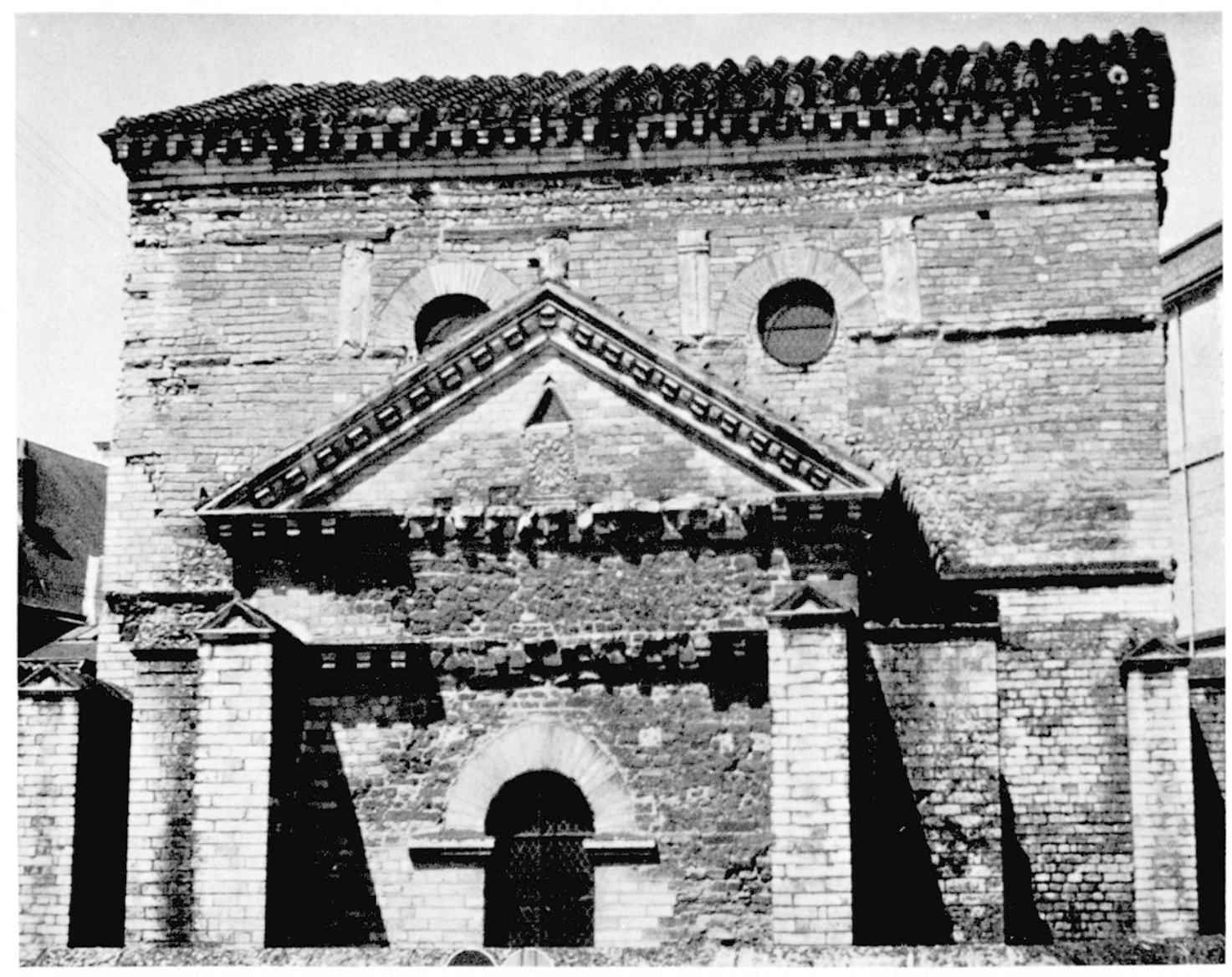

21. Façade est et absidiole centrale.

logues poitevins qui suivaient ses travaux et en avaient vu les amorces, il maintint son point de vue et le $\mathrm{P}$. de la (iroix a noté que le mortier de ces constructions est différent de celui des murailles romaines.

Cependant, nous ne prétendons pas pouvoir donner une explication indiscutable pour tous les faits observés. Ainsi la corniche en escalier à l'est, qui se trouve à la base de la zone à arases, est soutenue par des pilastres dont le milieu est occupé par une arète plate et leurs chapiteaux, qui paraissent avoir été de bonne sculpture sont coupés à la moitié de la corbeille pour les adapter à la hauteur voulue. Au nord et au sud, on a pris un parti meilleur, celui de raccourcir les pilastres qui sont plats, sans arêtes, et de supprimer la hauteur en trop. Enfin, au sud, les arases supérieures ne sont pas parallèles mais se réunissent vers l'ouest pour rattraper un tassement de la maçonnerie ; toutefois la section du pilastre a été insuffisante pour le diminuer assez; il a fallu supprimer le tailloir. Les frontons décoratif́s à étoiles de brique des pignons, situés de chaque côté de la stèle centrale pour orner le pignon. ne sont plus à leur place primitive qui devait se trouver directement au-dessus d'une corniche absente de leur base, qui maintenant n'est plus fermée.

Intérieurement (fig. 23), à quoi correspondent ces observations? On remarque là aussi l'existence du petit appareil cubique sur les murs latéraux et, à l'est, entre et derrière les arcalures qui accompagnent l'arc de l'absidiole; le parement allongé apparait aux angles, comme liaison et pour soutenir les arcs. En cet endroit, il est d'ailleurs le fruit d'aménagements ; en effet, la cella du baptistère, qui primitivement était une salle rectangulaire simple et dont nous ignorons si elle eut une 
décoration, fut postérieurement percée de trois arcs pour permettre l'adjonction de trois absidioles. Celles des côtés étaient alors rectangulaires ; les substructions l'indiquent. Une utile photographie ${ }^{17}$, antérieure à la restauration de 1855 , montre, plus clairement que le dessin de Gailhabaud, le forage du mur antique pour insérer l'arc à claveaux étroits et allongés dont la face intérieure nous apparaît seule aujourd'hui, l'autre étant dissimulée par la reconstruction récente de l'ahsidiole.

Vers le même temps, le mur est était doublé par une arcature de trois éléments, celui du centre de $0,27 \mathrm{~m}$ de profondeur, encadrant très heureusement l'ouverture de l'absidiole centrale. Le collage de cette arcature apparaît nettement sous le plein cintre et l'on peut remarquer dans l'espace situé entre ses claveaux et ceux de l'entrée, une certaine maladresse dans l'agencement de la bordure du percement, en même temps qu'un léger surplomb sur le niveau du mur sous-jacent. A la base des fenêtres, le mur supporté par cette arcature et qui forme tablette est, lui aussi, ajouté ; il déborde de 0,26 à $0,27 \mathrm{~m}$ sur celui du fond. Le collage y est visible et on peut passer une lame par endroits entre les deux maçonneries. Son tassement fait même que l'une des bases des colonnettes est suspendue, ce qui n'est pas visible du sol. La surface des murs nord et sud fut alors recouverte d'un parement neuf allongé qui remplace presque partout le petit appareil cubique, sans doute usé ou peutêtre brûlé par l'incendie qui a quelque peu calciné certaines colonnes de marbre. Mais nous devons remarquer au passage combien la restauration de Joly-Leterme fut indiscrète aux trois murs du rez-de-chaussée. Nous avons déjà signalé la disparition d'un arc figuré par Gailhabaud. C'est ce même revêtement à éléments barlongs que nous retrouvons dans les reprises diverses, un peu partout, à l'intérieur comme à l'extérieur et dans les parties hautes à partir de la base des fenêtres.

On a eu trop souvent coutume d'attribuer à la période carolingienne le petit appareil allongé. C'est là une erreur : on le rencontre dès l'époque romaine, d'abord en boutisses, pour lier les angles avec plus de solidité. Sans sortir de Poitiers, le grand monument gallo-romain qui apparait dans la cave du presbytère de Saint-Porchaire (cf. Gallia, IX, 1951, p. 104), offre de larges surfaces ainsi parementées.

Les fenêtres en plein cintre, lorsqu'elles furent construites, s'ouvraient vers l'intérieur sur les trois côtés avec un ébrasement sur une partie du mur en retrait par rapport à celui qui soutient l'arcature et le parement des côtés. Elles furent bouchées pour former des oculi, certainement peu de temps après avoir été restaurées, avec un appareil qui extérieurement correspond à peu près à celui du mur. Vers l'intérieur, des colonnes de marbre à chapiteaux en calcaire du pays supportent les impostes continuées en corniches. Un arc en mitre forme arcature entre elles. Par un curieux aménagement, assurément voulu, la décoration extérieure inversera cette disposition et deux frontons triangulaires séparent un tympan en plein cintre, mais à l'étage qui domine les fenêtres.

Si la décoration interne en effet s'en arrête là, il n'en est pas ainsi au dehors où elle ne commence qu'au niveau des impostes des fenêtres et consiste en une série de pilastres, de frontons, de stèles et de corniches à modillons pris dans le mur, et sur les pignons avec marqueterie de brique et de calcaire.

Nous sommes en face d'un monument héritier des traditions romaines dans ses éléments constructifs d'origine. Lne grammaire décorative nouvelle, originaire d'Orient, est venue s'y ajouter par Ravenne, semble-t-il. Il faut penser que les Wisigoths ont occupé le Poitou des environs de 430 à 507 ; s'ils n'y ont vraisemblablement pas entretenu les monuments catholiques, les ouvriers de ce temps ont subi l'influence de leur civilisation pour une bonne génération. On est surpris par l'aspect général du baptistère et l'emploi systématique du petit appareil allongé dans sa restauration. Et c'est bien, à la couleur près, la silhouette de l'architecture en brique et du tombeau de Galla Placidia qui surgit avant toute réflexion devant les ycux. Émile Mâle en avait été frappé. Que les acanthes romaines, les perles et 

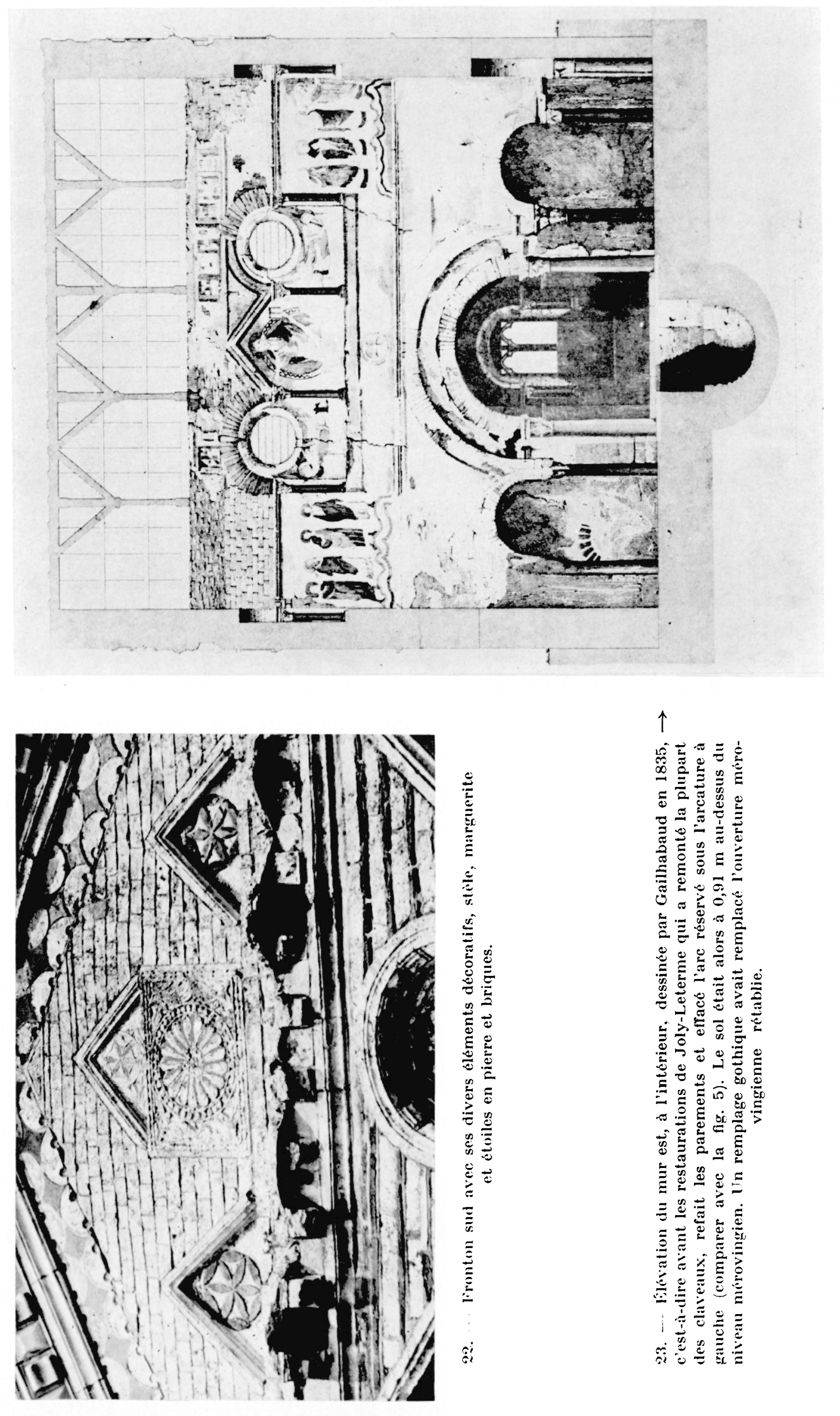

$\uparrow$

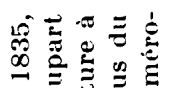

๘

胥类

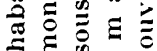

可苟

บ

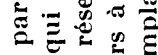

$\&$ \&

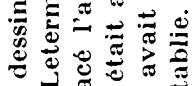

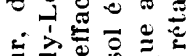

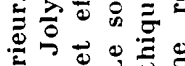

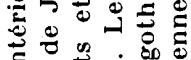

की

3 政

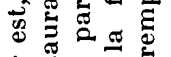

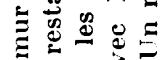

三承苛

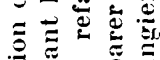

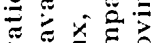

象苛焉

完

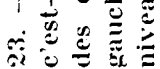


chapelets, les pointes de diamants, les corniches et leurs modillons soient mélangés à l'étoile et aux marguerites sur ces stèles ou ces tympans, s'explique aisément. En bref, l'extérieur fait penser que si la muraille de petit appareil presque cubique du Ive siècle a été conservée au moins jusqu'à la hauteur des fenêtres, et mème probablement jusqu'aux impostes et à la corniche qui les continue, elle a été reprise à partir de leur base et un parement nouveau de moellons appareillés allongés a réparé l'ancien partout où cela était nécessaire, à l'intérieur comme à l'extérieur. Il est vraisemblable que les fenêtres existaient dès le Ive siècle, pour éclairer la cella, mais qu'à la suite d'un abandon assez long, au cours de la période de persécution wisigothique, elles ont dû être comprises dans la réfection du temps de l'appareil allongé. Leurs claveaux étroits sont bien du type de ceux des grandes arcades et arcatures intérieures.

Il semblerait d'ailleurs, nous l'avons dit, que la restauration ait été faite en deux fois avec incendie intermédiaire.

B. Décoration des parties hautes. - La décoration très particulière des parties hautes du baptistère Saint-Jean (planche I), sans oublier les chapiteaux, mérite d'être examinée

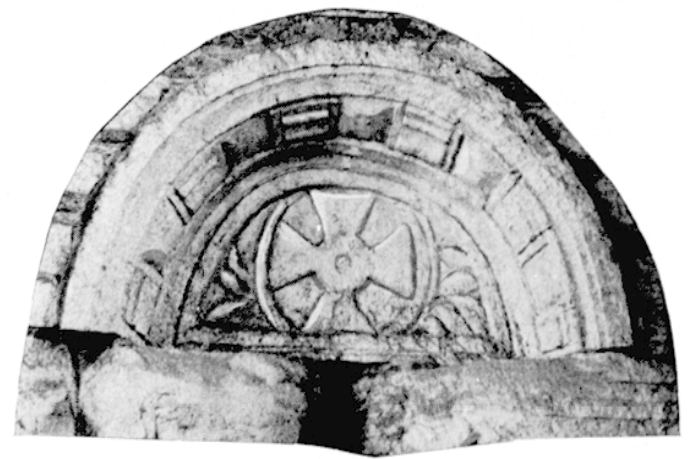

24. - Faux tympan du côté sud. avec soin. Elle a été remarquée bien des fois sans qu'on puisse la rattacher étroitement à l'un des grands courants artistiques connus.

Elle s'amorce extérieurement sur les trois côtés éclairés au-dessus de la corniche située au niveau des impostes des fenêtres, par douze pilastres à chapiteaux plats encadrant les demi-cintres de celles-ci et soutenant une corniche en escalier. Au nord et au sud, au-dessous de celle-ci et dans une zone de mur où le petit appareil allongé alterne avec des arases de briques, sont encastrées trois arcades moulurées, celle du centre en demicercle bouchée par un faux tympan (fig. 24) sculpté d'une croix pattée entre des feuillages dérivés de l'acanthe, les autres en triangle portant, au centre, des étoiles ou des marguerites avec les écoinçons ornés, eux aussi, de feuilles ou même d'une singulière tête de monstre. Deux de ces dessins en étoiles (fig. 25 et pl. I, en bas, à gauche) sont encadrés de files de perles suivant le triangle; ils ont un certain relief. Les deux autres sont méplats et ne paraissent pas sculptés de la même main.

Les frontons sont entourés d'une corniche saillante à modillons suivant la base et les rampants; au-dessous de ceux-ci, une élégante frise en marqueterie de calcaire à motifs de peltes alternant avec des carrés curvilignes concaves en briques occupe les sommets des murs. Sur le plat du pignon, deux motifs triangulaires comparables à ceux de l'étage sous-jacent, mais ici les étoiles, formées de fuseaux ou pétales de briques, encadrent une sorte de stèle que l'on retrouvera sur l'absidiole est (fig. 26). Elle est formée d'une partie rectangulaire bordée de perles et ornées d'une large marguerite avec des feuillages dans les écoinçons, sous un fronton triangulaire mouluré qui s'orne d'une rose en son centre. 


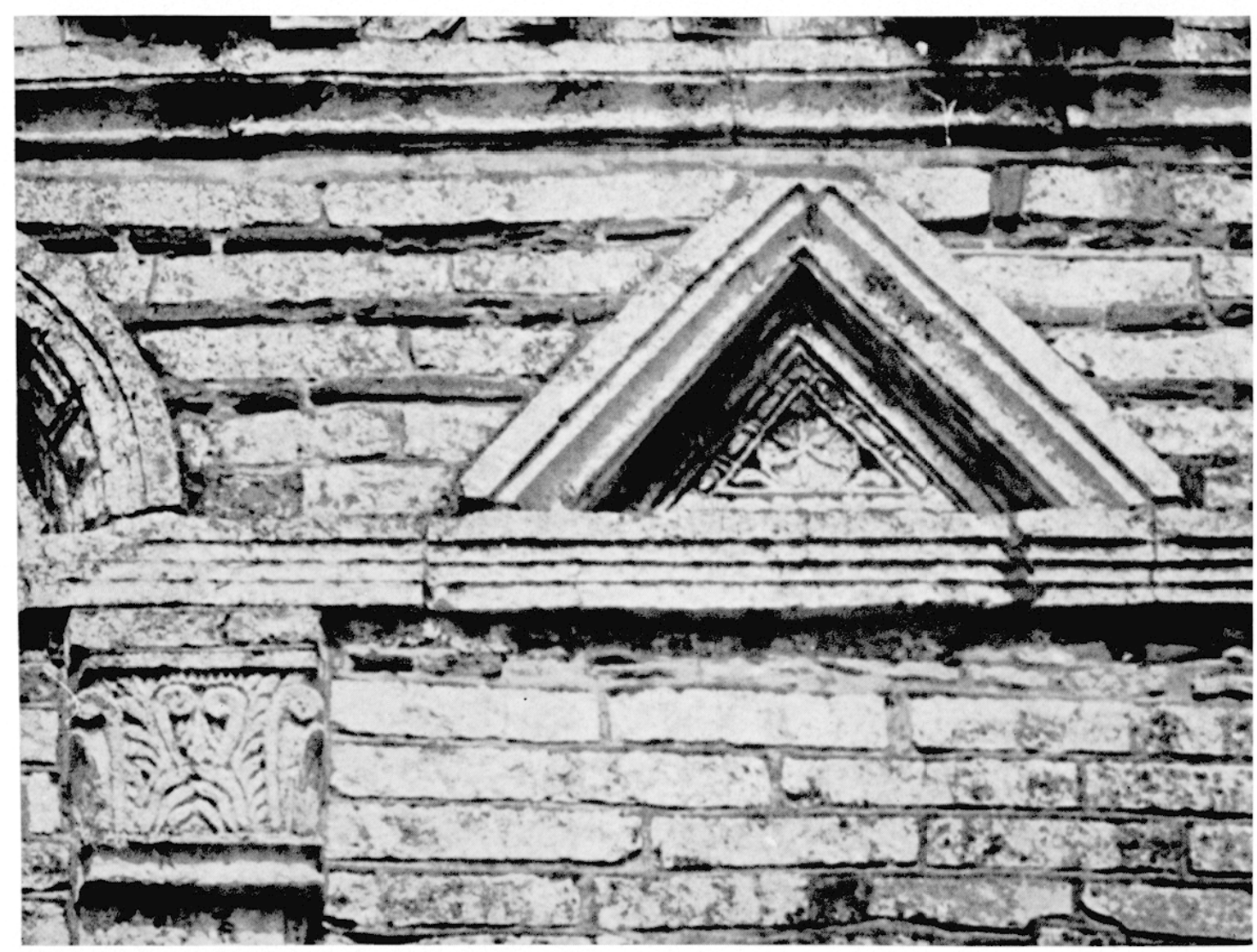

25. - Détails du cỏté sud.

L'unité d'origine de ces ensembles est évidente : mêmes sujets ; roses grandes ou petites étoiles, feuilles et acanthes réduites à l'état schématique, chapelets de perles, le tout façonné avec une maladroite rusticité. Ce n'est pas l'œuvre d'une seule main car certains éléments sont plus vigoureusement traités que d'autres. Rappelons que les modillons sculptés sous les arcs en plein cintre ont leurs pareils sous les rampants des pignons. Tous ces motifs sont plus ou moins mutilés, installés à peu près symétriquement, sans souci de distances exactes. Ils donnent l'impression d'un remploi sur place dans une maçonnerie refaite dont le parement neuf a dissimulé d'ailleurs assez mal les reprises. Les marqueteries des briques ne sauraient être postéricures aux autres motifs, tant la sculpture des écoinçons est semblable à celle des motifs sous-jacents.

A l'intérieur, ces parties hautes ne présentent comme motifs sculptés que les chapiteaux de calcaire, à peu près ignorés de ceux qui ont écrit sur le baptistère. Il est incontestable qu'ils sortent d'un même atelier. Leurs éléments décoratifs, acanthes, feuilles et perles à peine plus soigneusement sculptées mais mieux conservées qu'à l'extérieur sont de même inspiration. Si aucune des corbeilles des arcatures hautes n'est absolument semblable, leur dessin est cependant très monotone : aux angles, larges feuilles découpées ou recouvertes de feuilles plus petites. A leur jonction se détachent des caulicoles terminées en volutes sous les angles des abaques arqués, au centre desquels se distingue un dé orné. 
Les écoinçons déterminés par l'intervalle des caulicoles et l'abaque sont garnis de motifs végétaux simples ou dérivés de décors antiques, perles, cordelières, feuilles en série ou autres. Ces chapiteaux faits par un atelier local varient assez peu de taille : $0,30 \mathrm{~m}$ à $0,34 \mathrm{~m}$ et leurs bases s'adaptent assez bien aux colonnes de marbre pour lesquelles elles ont dû être faites. Les chapiteaux des pilastres sont une sorte d'interprétation maladroite de ceux des arcades supérieures. On y retrouve les feuilles des angles schématisées ainsi que les caulicoles épanouies en volutes aux angles, le centre de la corbeille occupé par d'autres caulicoles à direction hésitante sur un fond de feuilles méplates. Là cncore plusieurs mains inégalement habiles ont reproduit les menus dessins, à moins qu'il n'ait fallu, après incendie, remplacer les motifs trop abîmés.

Ce mode ornemental des stèles n'a pas été unique à cette époque en Poitou. Des motifs de Mazerolles (Vienne) et deux autres venant probablement de N.-D. l'Ancienne, à Poitiers, le prouvent. On en cherche vainement de ce type ailleurs; Mazerolles, soulignons-le, a été restauré, non pas créé par Ansoald. Cette particularité artistique locale nous empêche de penser à une importation. Il s'agit en fait d'une école très locale qui s'apparente à celle des tailleurs de sarco-

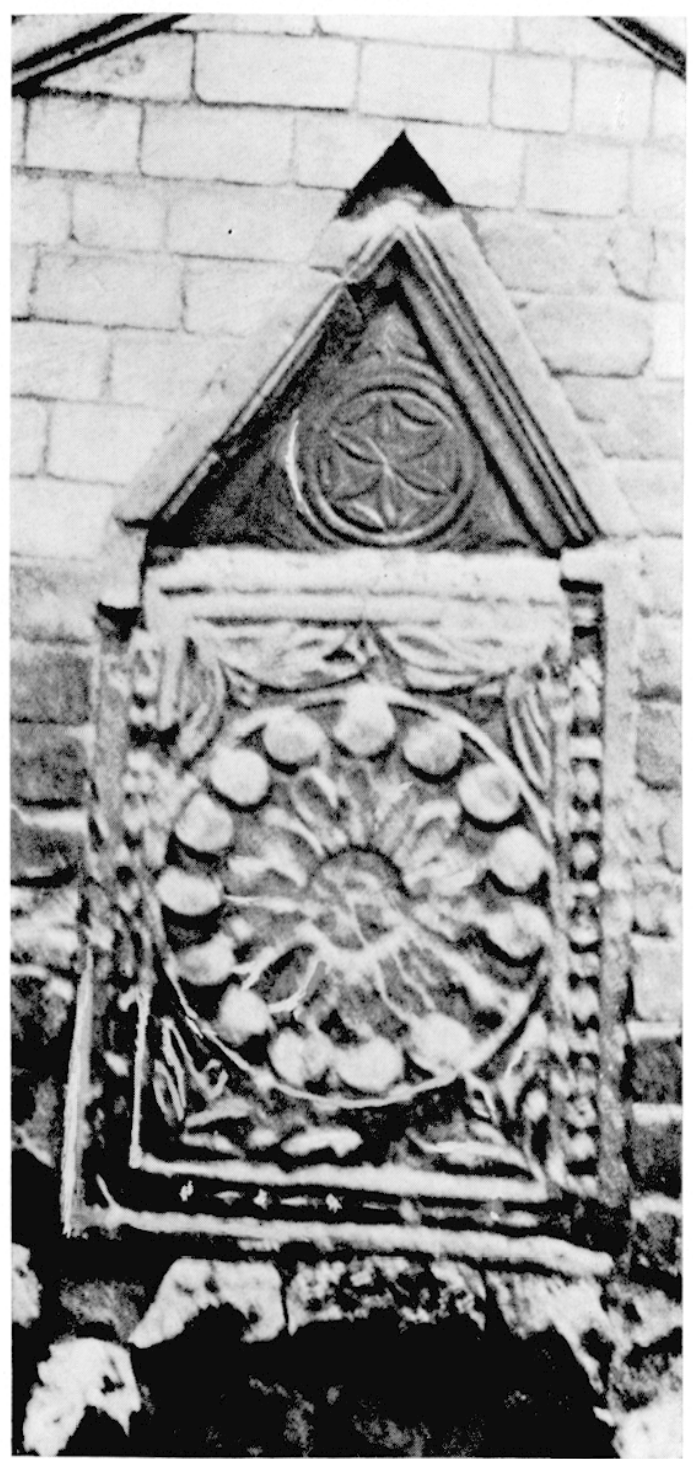

26. - Stèle du pignon de l'absidiole. phages à couvercles très décorés, comme ceux d'Antigny ou de Béruges. Ces motifs, étoiles à six branches, marguerites, croix légèrement pattées à branches égales, traités de façon méplate sont d'origine orientale, mais les thèmes ornementaux romains les accompagnent toujours selon un caractère commun au style de Ravenne et à celui du Sud-Ouest depuis le ve siècle. L'art wisigoth d'Espagne s'est nourri aux mêmes sources et a fourni des stèles funéraires ${ }^{18}$ qui ne sont pas sans faire songer à celles, décoratives, des pignons de Saint-Jean. Si les symboles de base sont les mêmes, toutefois ils sont traités par un ciseau bien différent.

Disons qu'ici l'art antique, dans ses moulurations et ses motifs traditionnels jette un dernier éclat, se mariant à ces influences nouvelles qui vont le submerger.

(18) Plig y Cadafalci, L'art wisigothique, Paris, 1961, pl. X, notamment b. 
C. Les chapiteaux de marbre. - Le P. de la Croix considérait qu'ils étaient des remplois antiques à l'exception de ceux, plus simples, qui auraient été exécutés à l'époque mérovingienne pour compléter la série. Ils ont été étudiés depuis par Ch. M. Raymond ${ }^{19}$, l'abbé Plat ${ }^{20}$, M. J. Hubert et enfin de façon très approfondie par M[1le Fossard ${ }^{21}$ qui a suggéré des rapprochements souvent précieux ; ainsi deux corbeilles de Poitiers et de Saint-Denis ont des analogies saisissantes. Mais il n'en est pas toujours ainsi et les chapiteaux du baptistère Saint-Jean ne sauraient être comparés aux somptucuses réalisations de Jouarre. Cies deux séries ne peuvent être du même temps et n'appartiennent pas à des types correspondants. La question est d'ailleurs beaucoup moins simple que ne l'a exposée

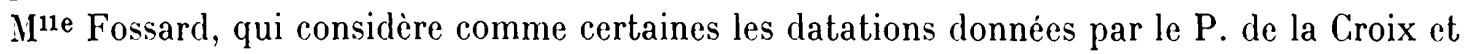
appuie sur elles presque la moitié de ses conclusions. Or, le grand fouilleur avait hésité avant de fixer la seconde moitié du vir ${ }^{\mathrm{e}}$ siècle pour époque de la seconde campagne : "J'ai fait remarquer, dit-il, que toutes les pierres sculptées qui décorent les murs du baptistère construits à l'époque mérovingienne ont un faire artistique propre au vi e siècle et inconnu au $v_{11}{ }^{\mathrm{e}^{22}}$. Et il conclut au remploi. S'il choisit néanmoins cette dernière époque, c'est pour faire coïncider la reconstruction du sommet avec l'épiscopat d'Ansoald, restaurateur ou fondateur de nombreux édifices dans son diocèse. Malheureusement, aucun des documents qui énumèrent les nombreux travaux encouragés par le prélat ne mentionne le baptistère! Cela ne découragea pas le digne jésuite qui déclara devant le silence des textes que si son action fut aussi étendue, Ansoald n'a pu oublier le baptistère de sa métropole ${ }^{23}$.

Cette restauration, qui donnait à Saint-Jean une allure si proche du style de Ravenne et qui rappelle à tant d'auteurs ${ }^{24}$ la silhouette du tombeau de Galla Placidia ne peut être très éloignée de la fin de l'occupation wisigothique. Il s'est d'ailleurs passé au vie siècle un événement, autrement important que l'épiscopat d'Ansoald, c'est la victoire de Clovis sur Alaric en 507, done la défaite de l'arianisme au lendemain d'une persécution qui ne manqua pas de se répercuter sur les monuments ; Grégoire de Tours (H. F. II, 25) décrit l'état de misère et d'abandon dans lequel étaient tombés les édifices chrétiens à cette funeste époque ; il devint urgent de rendre à ceux-ci leur lustre pour les besoins de l'orthodoxie renaissante. Si le baptistère a été ruiné pendant la seconde moitié du ve siècle, et il semble bien qu'on ne puisse placer à aucun autre moment la décrépitude qui a nécessité sa rénovation, aucune invasion n'ayant ravagé Poitiers ensuite pendant longtemps, on n'a pas pu attendre beaucoup de décades avant de remettre en état un lieu de culte aussi essentiel. Il est également impossible, comme le voyait déjà le $P$. de la Croix, de rapprocher structure et ornementation de celles de l'hypogée des Dunes, que l'on accepte de dater du début du viri ${ }^{\mathrm{e}}$ siècle. Cette époque de la fin du viI ${ }^{e}$ siècle, acceptée comme un postulat, fausse donc regrettablement au départ l'étude par ailleurs si intéressante de Mile Fossard.

(19) Gazelle des Beaux Arts, 1914, p. 105-109.

(20) L'Archileclure religieuse en Touraine, Paris, 1939.

(21) Les chapileaux de marbre du VII'e siècle en Gaule. Slyle el évolulion, dans Cahiers archéologiques, II, 1945, p. $69-85$.

(22) Elude sommaire, p. 60.

(23) Elude sommaire, p. 61 et $\mathrm{s}$.

(24) Voir p. 3, n. 1 et Émile MÂle, La fin du paganisme en Gaule, p. 221. 
Nous avons voulu reprendre méthodiquement l'étude des marbres du baptistère SaintJean. Toutes les colonnes viennent des Pyrénées et les chapiteaux, de Saint-Béat, mais les uns sont en marbre blane fin et les autres en marbre gris. En voici le tableau ${ }^{25}$ :

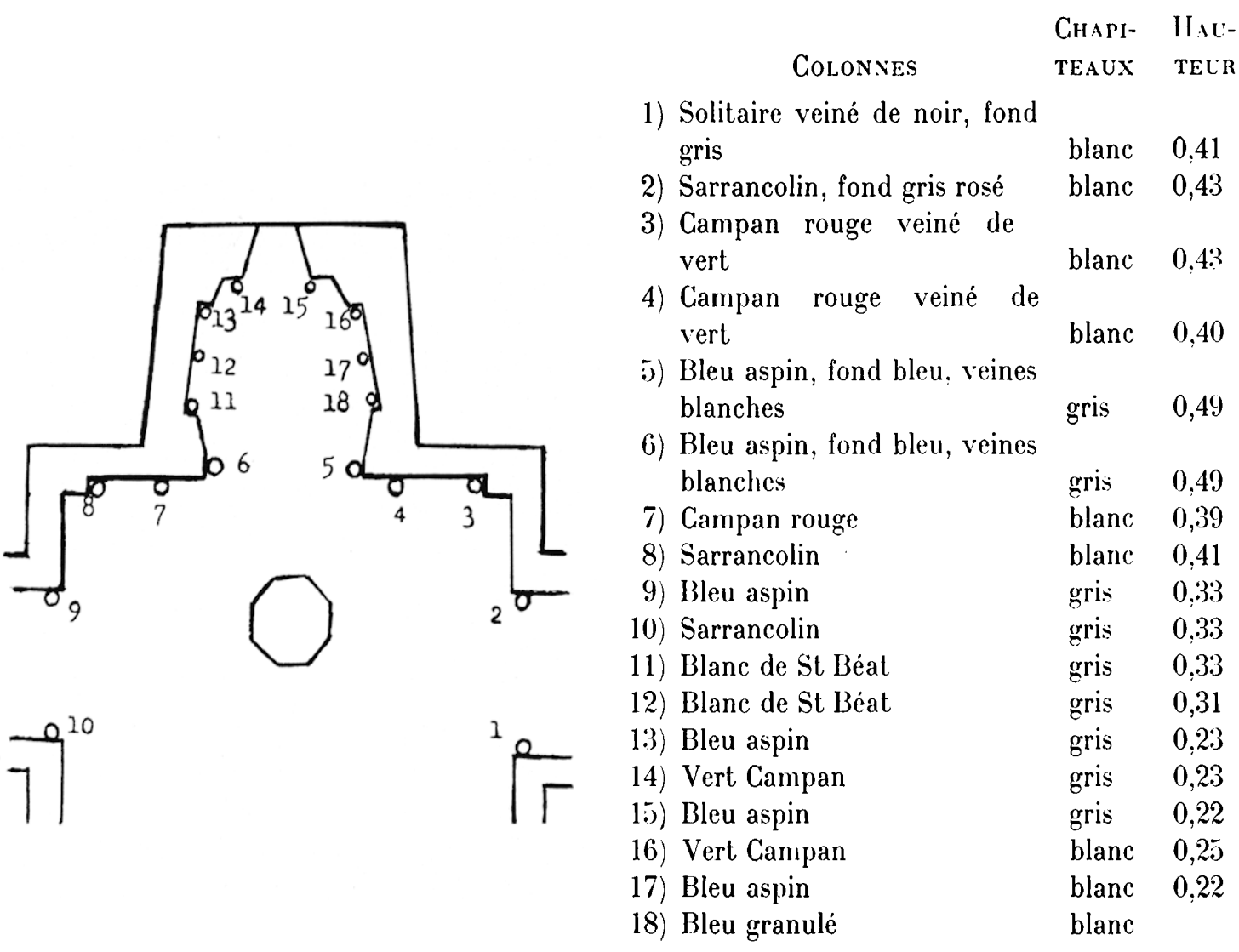

Personne n'a discuté le fait que les colonnes disparates, plus ou moins mutilées, dont les astragales présentent des profils variés lorsqu'ils subsistent, proviennent d'origines diverses et de monuments détruits ; mais on tient à ce que les chapiteaux qui ne sont pas plus conformes et dont les diamètres des bases ne s'accordent pas avec ceux des supports, aient une origine unique.

Il faut distinguer par leurs tailles, provenant de leurs fonctions, trois séries : $1^{0}$ les huit de la salle baptismale, $2^{\circ}$ les deux plus importants qui précèdent l'absidiole est, $3^{\circ}$ les huit qui ornent les arcatures latérales et la fenêtre de celle-ci, dont la taille est généralement plus petite que celle des autres ( $\mathrm{n}^{0} 11$ excepté). Il semblerait que si ces chapiteaux ont été commandés pour un monument dont le plan de restauration et d'agrandissement, était, prévu, ils devraient offrir une unité de matière et surtout de hauteur assez uniforme. Or, dans le premier groupe, du plus petit $(0,33 \mathrm{~m})$ au plus grand $(0,43 \mathrm{~m})$, existe une différence de près d'un quart et dans le dernier (de $0,22 \mathrm{~m}$ à $0,33 \mathrm{~m}$ ), du tiers. Les corbeilles centrales, plus amples et de type nettement plus ancien sont l'une et l'autre de même matière et de dimensions identiques. Le P. de la Croix qui avait bien senti ces rapports inégaux et surtout la variété des styles, considérait que ces marbres provenaient de 12 monuments

(2:) Les qualités des marbres sont relevées d'après le marbrier consulté par le P. de la Croix (Arch. Vienne, notes du P. de la Croix, carton A 14). Nous avons relevé les dimensions et vérifié les indications. Notons ici que les $n^{o s} 13$ et 14 ont été retravaillés en 1852 chez Pincé, marbrier à Poitiers. 
différents, ce qui est peut-être beaucoup dire, mais toutes ces sculptures n'ont assurément pas la même origine ni une date de fabrication commune. Certaines pourtant sont étroitement comparables ; leur ornementation les accorde le plus généralement par paires; leur marbre est alors de même nature et leur taille proche ou identique. Il faut ainsi grouper 1 et 2, 3 et 8, 4 et 7,9 et 10, les six premiers étant en blanc de St-Béat, les deux derniers en gris. Nous avons déjà noté l'analogie et les dimensions identiques de 5 et 6 , mais l'un est corinthien bien proche de celui de Manglieu (P.-de-D.) de même style, et l'autre porte au-dessus des acanthes des dauphins affrontés aux angles, qui n'ort ici rien de chrétien, si ce n'est l'utilisation d'un motif païen que le christianisme a changé de sens.

La variété de ces dessins est d'ailleurs trop contrastée pour qu'on puisse accepter l'existence d'un lot unique. Ils sont le produit d'ateliers héritiers d'une longue pratique prolongée de Trajan aux invasions sarrazines du début du vine siècle. Traditionnels et mème un peu routiniers il est très naturel de leur voir employer fort longtemps la grammaire décorative romaine, tantòt classique, tantôt schématisée ou vivifiée par une heureuse liberté venue de Ravenne et d'Orient qui donne aux plus beaux élégance et diversité. Certains ( 1 et 2 ) ont en quelques endroits été travaillés au trépan, procédé cher aux ouvriers byzantins. Des détails comme les trois crossettes successives du chapiteau situé à gauche de la fenêtre d'axe, sont des éléments trop fréquents au nord de l'Adriatique pour ne pas donner une piste. On les voit ainsi répétées à satiété sur des bordures et des frises notamment aux musées paléochrétiens d'Aquilée et de Saint-Vital de Ravenne. Il est certain que les ateliers pyrénéens ont été sensibles aux modes artistiques nouvelles sans perdre pour cela toutes leurs habitudes anciennes.

Colonnes et chapiteaux de marbre proviennent d'origines diverses ${ }^{26}$, dépeçage de monuments détruits et, pour compléter ce qui manquait, le commerce des carrières pyrénéennes, mais il s'est écoulé bien du temps entre la fabrication des corbeilles de l'entrée du chœur et celles des angles de la salle baptismale. Il faut élargir de plusieurs siècles le cadre trop étroit de l'étude de M"le Fossard pour y loger les chapiteaux de Saint-Jean et sans doute quelques autres ${ }^{27}$. Les corbeilles antiques de l'église de Montcaret (Dordogne), que cet auteur ne paraît pas avoir connues, seraient bien difficiles à classer si l'origine n'en était évidente.

Telles sont les réflexions que nous a suggérées l'étude, on peut dire à la loupe, de la surface des trois murs anciens de la cella et de l'absidiole. Elles indiquent à quel point il est difficile d'interpréter les restaurations du baptistère.

Les siècles qui ont suivi la période carolingienne ont assurément modifié l'aspect général de l'édifice. Une seule des salles jumelles subsiste intacte. Le narthex rectangulaire a été détruit avec les deux petites sacristies probablement à la fin du $\mathrm{x}^{\mathrm{e}}$ siècle. Sans doute avaient-ils été moins bien entretenus que la cella baptismale et plus ébranlés par la vétusté ou l'incendie. Les angles ouest

(26) Cette question des origines diverses des chapiteaux de marbre est constante : la crypte romane de San Pietro de Tuscania, dans le Latium, où la variété autant que la disproportion des corbeilles en présente un exemple remarquable. Et d'ailleurs, lorsqu'on trouve ces chapiteaux isolés, hors de tout ensemble, comment penser à autre chose qu'à un remploi ?

(27) Le chapiteau de Corme-Royal (Charente-Maritime), signalé à la p. 82 de son étude, n'a certainement rien à voir avec les séries pyrénéennes courantes. Il imite les belles corbeilles ravennates. Ses dimensions : hauteur 0,61 , largeur au sommet de la corbeille 0,83 , à la base 0,50 , le mettent tout-à-fait à part. Poli par les frottements il n'offre pas l'aspect, la couleur ni la cassure saccharoïde des marbres. Au no 10, le P. de la Croix note : "pas de chapiteau n. Celui qui s'y trouve actuellement, identique au no 9 , a dù être récupéré parmi ceux qui provenaient des fouilles. Il est soutenu par une console métallique. Les deux autres retrouvés aussi dans les mêmes circonstances proviennent sans doute des arcs qui faisaient communiquer le narthex et la salle baptismale. L'un d'eux (FossarD, pl. VII, nº 5) a été coupé à la base comme si on l'avait rejeté après avoir tenté de l'ajuster. 
de la cella furent repris avec un moyen appareil solide, en même temps que le mur séparant le baptistère du narthex et ses passages. Ceux-ci furent au moins partiellement remplacés par trois arcades extradossées suivant un usage qui n'est déjà plus de mode à l'époque romane dans la région. $A$ la salle carrée en succède une autre polygonale, où cinq côtés sont substitués à trois vers la porte centrale. Sur le mur de petit appareil remployé et assez régulier, s'ouvrent deux petites fenêtres, à linteau échancré et où les claveaux sont figurés. Celle du centre un peu plus vaste reste encore modeste. Une corniche sculptée de nattes et à modillons méplats terminait le mur ; quelques éléments subsistent dans la corniche romane à sujets grotesques qui lui a succédé sans doute au temps où l'entrée a été complétée par un clocher arcade. Ce clocher fut reconstruit en 1389, époque à laquelle le corps de ville accordait pour cela une subvention au curé (Arch. Mun. de Poitiers, cart. 35 K 1). Est-ce au $\mathrm{x}^{\mathrm{e}}$ siècle ou plutôt à l'époque romane que les absidioles nord et sud, carrées, se transformèrent en hémicycles dont seules les bases existent? Il est difficile de se prononcer puisque les parties hautes sont entièrement reconstruites.

Pour être complet, rappelons qu'au xiI ${ }^{\mathrm{e}}$ siècle, vers 1120 estime M. Paul Deschamps, une fort belle décoration romane couvrit les murs de la cella. A l'est, sous l'arc en mitre, se voyaient le Christ de l'Ascension, entre deux anges volant horizontalement sous les oculi et, de part et d'autre, quatre apôtres. Au sommet des murs, courait un bandeau de grecques et de médaillons carrés portant des oiseaux, le tout d'un type très influencé par l'art romain. Sur les côtés, d'autres personnages, des paons et des monstres restent figurés au mème niveau. Enfin, quatre cavaliers garnissaient les extrémités des murs est et ouest. L'un d'eux était Constantin, l'empereur si souvent représenté aux façades des églises romanes de l'ouest, ici déterminė par une inscription.

A cette campagne de peintures à fresques succéda une nouvelle série gothique, étudiée par M. Marc Thibout qui la date de la première moitié du xiIr ${ }^{\mathbf{e}}$ siècle. Sur le cul-de-four de l'abside ${ }^{28}$, se développe un grand Christ de majesté dans un quadrilobe avec les quatre symboles évangéliques. Deux saints barbus se font face vers l'arcature et d'autres personnages assez eliacés remplissent les vides. Des anges thuriféraires s'inclinent au-dessus de l'arcature d'entrée. La muraille était occupée par des scènes de la vie de saint Jean-Baptiste, dont les épisodes débordent sur le mur de fond de la cella. D'autres motifs se laissent encore deviner ici ou là.

\section{RÉSunÉ}

$1^{0}$ Sur un sol arasé, truffé de constructions romaines détruites en 276 , installation au milieu du Ive $^{\mathrm{e}}$ siècle du baptistère, formé de deux salles sensiblement carrées, l'une baptismale, l'autre narthex (précédées de deux secretaria séparées par le couloir d'entréc) et de la piscine. Les fondations gallo-romaines rencontrées sont détruites sans en tenir compte lorsqu'elles gênent. De cette première construction subsistent la piscine et les trois murailles de la salle baptismale au moins en partie jusqu'à la hauteur des fenêtres. Il n'y a point là de place pour une cathédrale double;

20 Probablement pcu de temps après la persécution wisigothique qui a laissé le baptistère à l'abandon, et la victoire de 507 sur l'arianisme, restauration du baptistère et surélévation des murailles avec insertion de motifs décoratifs. A l'intérieur, doublement des murailles, celle de l'est sur arcature. Ouverture de trois absidioles; celle de l'est en trapèze à l'extérieur, polygonale à l'intérieur, contient un autel, les deux de côté sont rectangulaires ; utilisation des colonnes et chapiteaux en marbre d'origines diverses ;

(28) Cette voùte n'est pas primitive mais refaite au xiı ${ }^{\mathbf{e}}$ siècle. 
$3^{\circ}$ Ln incendic dont les traces restent visibles a obligé peu de temps après à rénover les parements qui sont désormais presque partout en petit appareil allongé et enserrent les motifs décoratifs plus ou moins bien remis en place.

L'étude des étages supéricurs remaniés au moins deux fois dès l'époque mérovingienne, en raison de rapiéçages partiels et non de reconstruction totale, offre une clarté moins satisfaisante pour l'esprit. Les limites de datation de ces travaux ne peuvent cependant s'étendre sur un temps très long ;

$4^{0}$ Fin $\mathrm{x}^{\mathrm{e}}$ siècle, on abat le narthex et les secretaria, remplacés par une salle polygonale. Les arcatures menant à la salle baptismale, modifiées. passent de deux à trois. Les absidioles latérales carrées sont reconstruites en hémicycle. C'est l'état qu'a rétabli la restauration du milieu du $\mathrm{xIx}^{\mathrm{e}}$ siècle.

\section{François EYGLN.}

\section{BibLIOGRAPHIE SOMMAIRE}

D. Martène et D. Derand, Voyage littéraire de deux bénédictins, Paris, 1717, in-40, I, p. 9.

Dreux de Radier, Journal Historique sur les matières du temps, dit Journal de Verdun, 1750 et 1751 .

Sracve, Mémoire sur les antiquités du Poilou, Poitiers, 1804, in-8º, p. 225-227.

Cacmont, Cours d'antiquilés monumentales, Caen, 1830 , in $-8^{\circ}$ et un album oblong, pl. LXIV. Bulletin Monumental de 1837.

Thibaudeat, Histoire du Poilou, éd. Ste Hermine, 1839, p. 7 et 8.

Mangon de la Lande, Dissertalion sur un tombeau romain, Poitiers, $s . d$. in- $4^{\circ}, 18$ p. (vers 1850 ). Gailhabald, Monuments anciens et modernes, Paris, 1853, in- $4^{\circ}, 2^{\mathrm{e}}$ volume (dessins de 1836). MÉrimée, Mémoire sur le temple Saint-Jean, s. d., in plano.

De Chergé, Guide du voyageur à Poiliers, 1872, p. 105.

Espérandiev, Épigraphie romaine du Poitou et de la Sainlonge, Paris, 1888, 2 vol. in- $8^{\circ}$ et Revue Poitevine el Saintongeaise, V, 1888-1889, p. 321-338; - Notice du Baplistère Saint-Jean de Poitiers, Poitiers, 1890 in- $8^{\circ}$.

FÉlicien Pascal., Le Baptislère Saint-Jean, dans Magasin Piltoresque, 15-11-1899.

La Groix (R. P. Camille de), Elude sommaire du baptistère Saint-Jean de Poitiers, Poitiers, 1904,

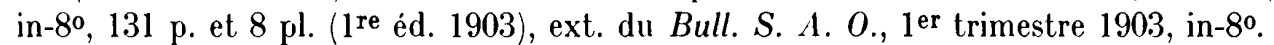

Сн. Marcer. Reymond, Le Baplistère Saint-Jean de Poiliers, dans Gazelte des Beaux Arts, 191415 , p. 105.

E. Ginor, Le Baplistère Saint-Jean de Poiliers et son musée lapidaire, Poitiers, 1934, 54 p., in-12º, ( $2^{\mathrm{e}}$ édit.).

Denrse Fossand, Les chapiteaux de marbre du VII siècle en Gaule, Style el évolution, dans Cahiers archéologiques, II, 1945, p. 68.

Pall Deschamps et Marc Thibout, La peinture murale en France. Le IIaul Moyen Age el l'époque romane, Paris, 1951, in-40, 178 p., pl.

J. Hubert, Le Baptistère de Poitiers et l'emplacement du premier groupe épiscopal, dans Cahiers archéologiques, VI, 1952, p. 135.

Marc Thiboct, Les peinlures murales golhiques de l'abside orientale du baptislère Saint-Jean, dans La Revue des Arts, 1955 .

H. Leclisco, Le Baptistère Saint-Jean, dans Dictionnaire d'archéologie chrétienne de Dom Cabrol et Dom Leclercq, Paris, XIV, 1, (1939), col. 1285 à 1312. 

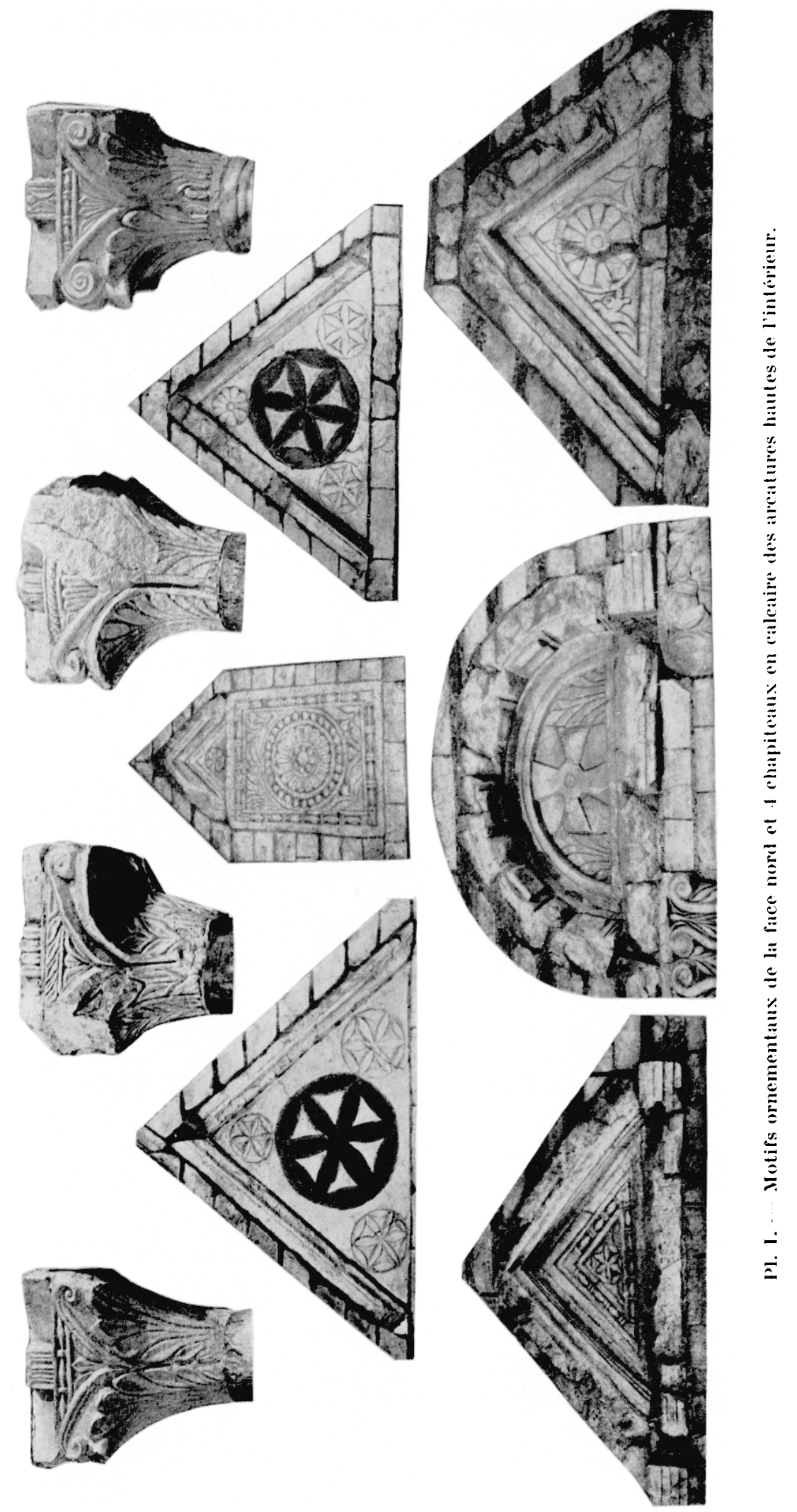

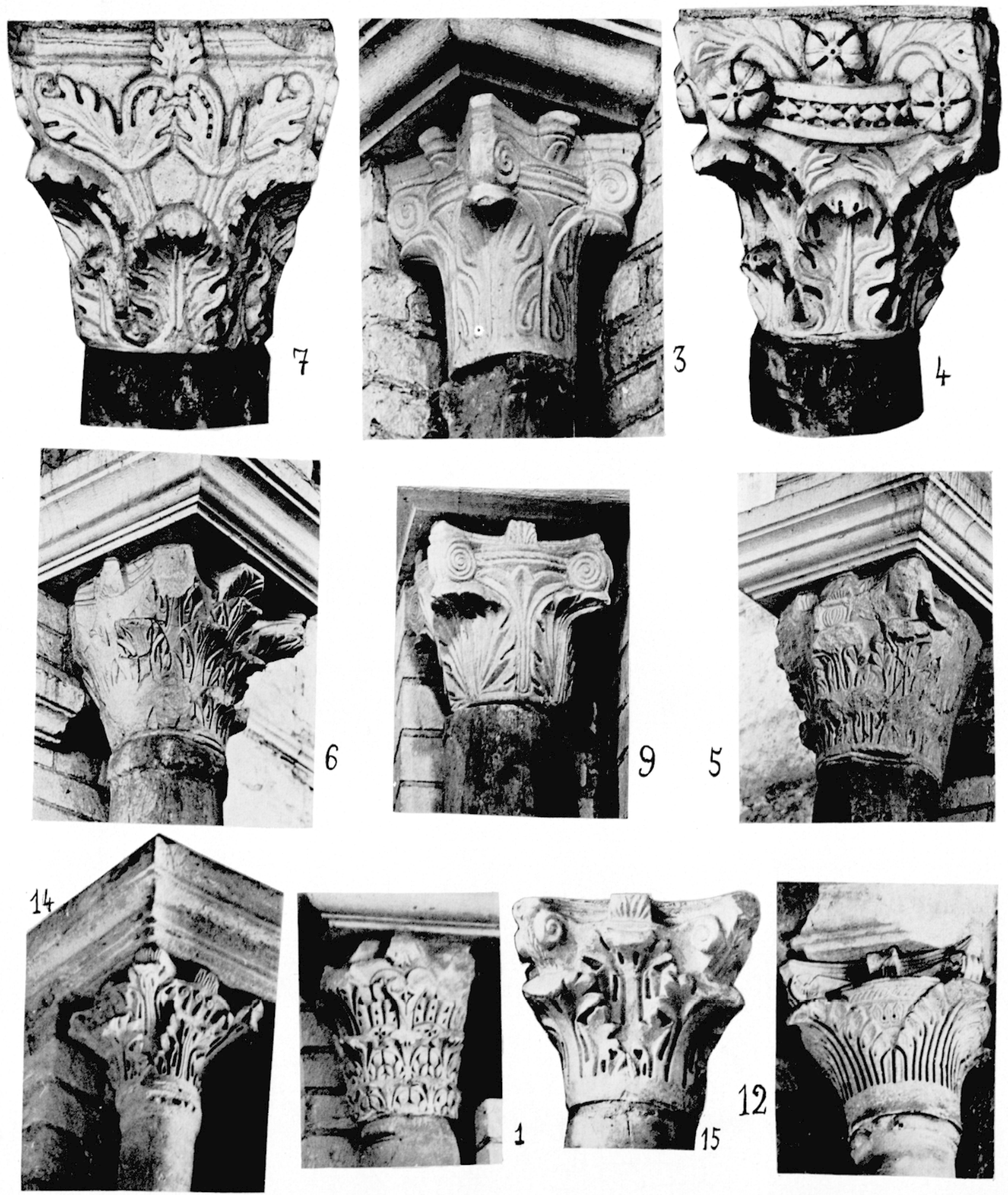

Pl. II. - Chapiteaux de marbre (voir schéma de la p. 162) - 1 et 2 sont identiques ainsi que 3, 8, 9 et 10, uu seul de chaque couple a donc été figuré. 5 , chapiteau portant des dauphins dont un subsiste partiellement. 


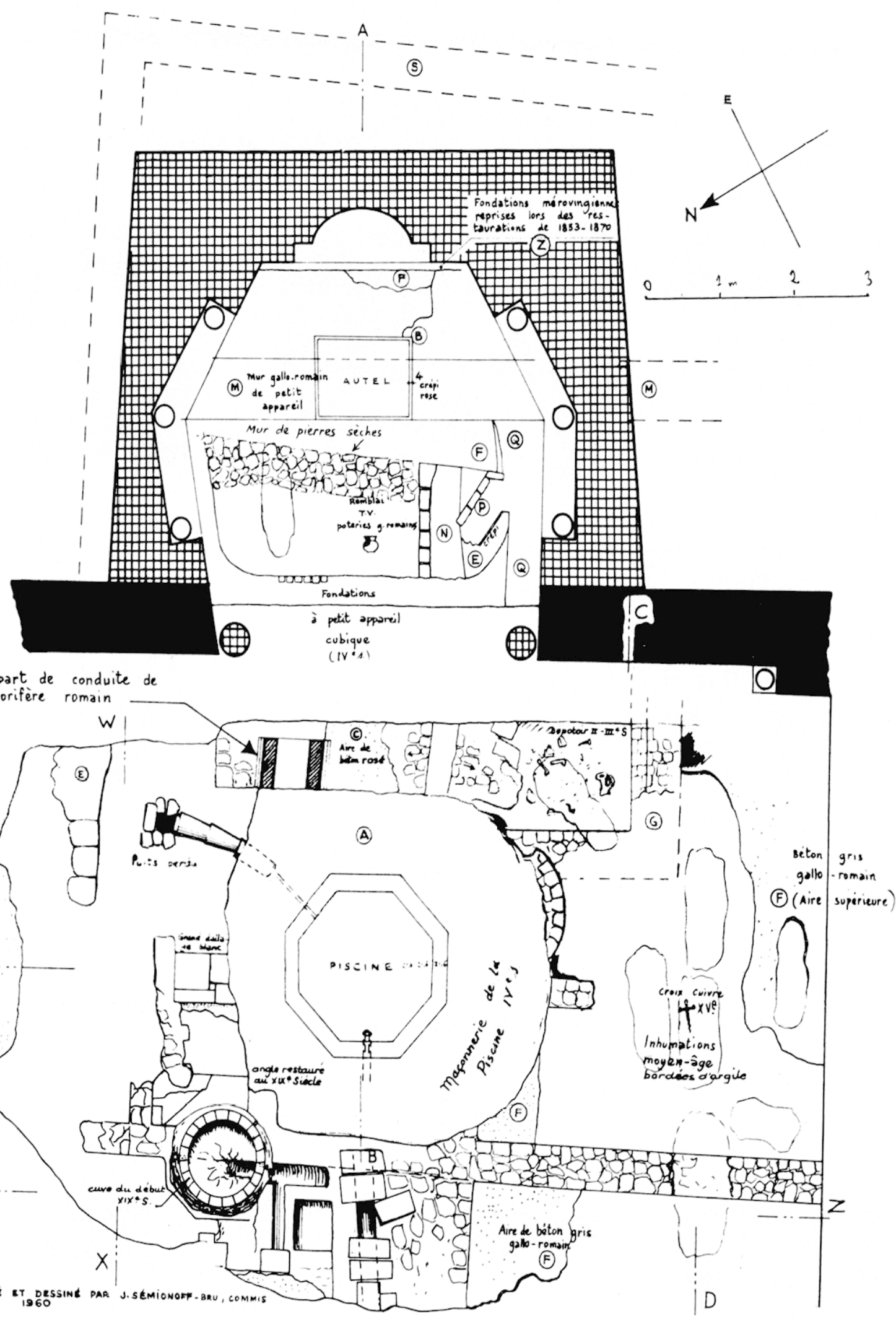

Pl. III. - Plan des fouilles du baptistère Saint-Jean. 


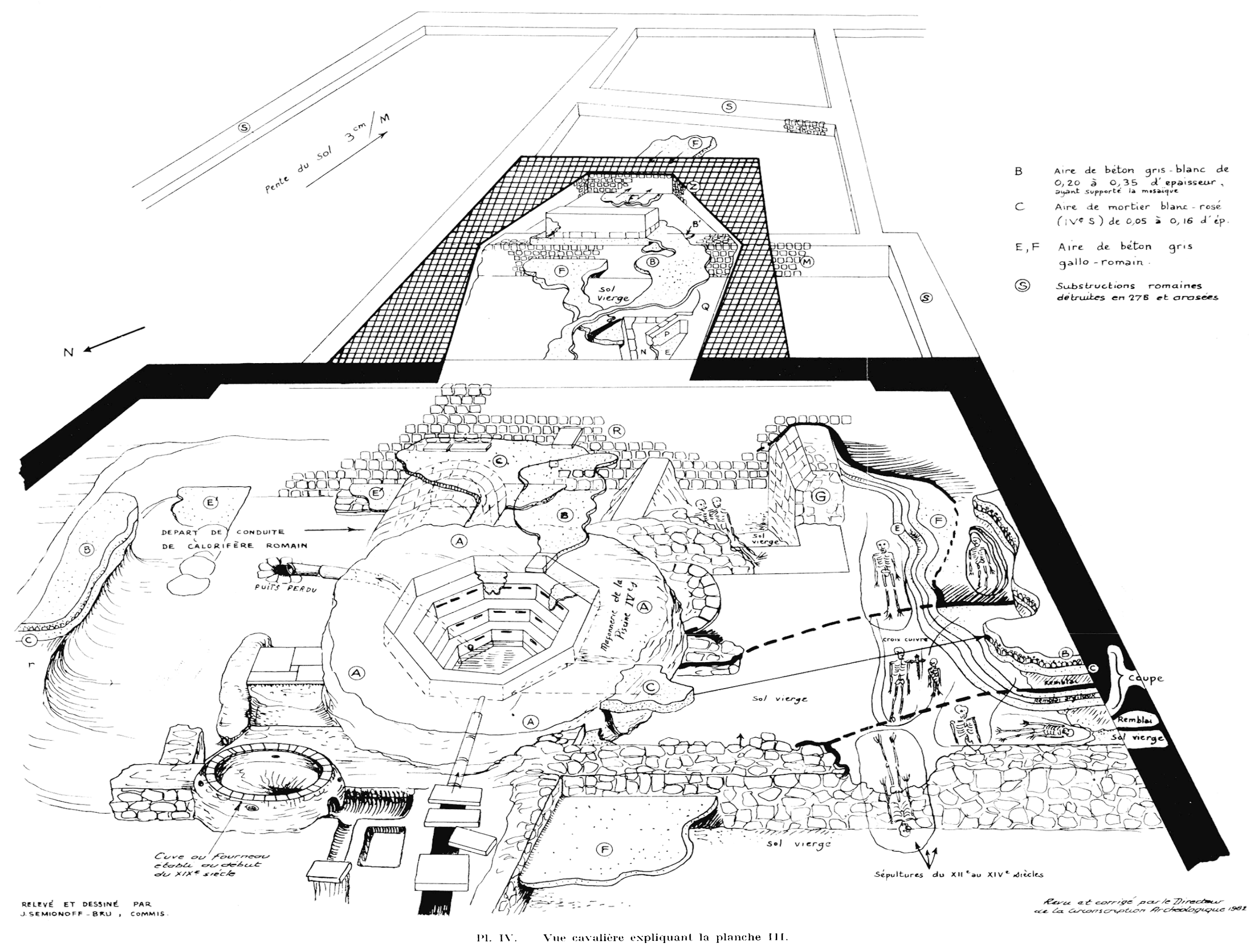



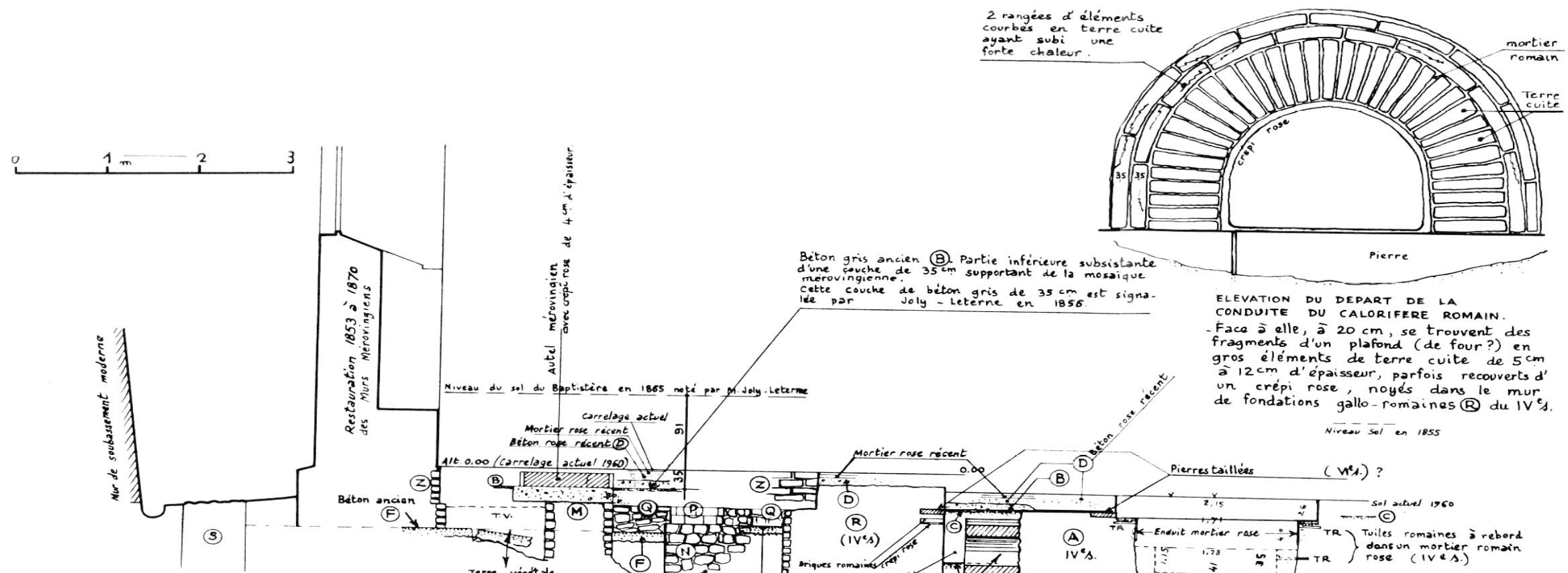

inférieure subsistante $x$

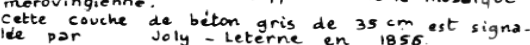
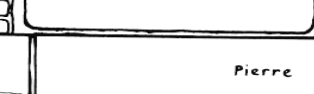

Pierre

DL DEPART DE LA Face à elle à $20 \mathrm{~cm}$ se tromain. fragments d'un plaforid (de four?) en gros élements de terre cuite de $5 \mathrm{~cm}$ un crépi rose, noyés dans le mur.

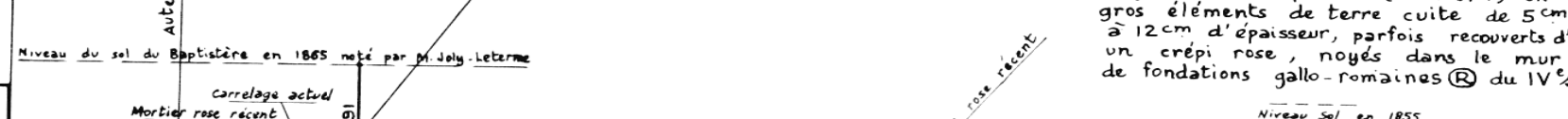

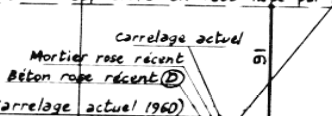
wivear sol en 1855

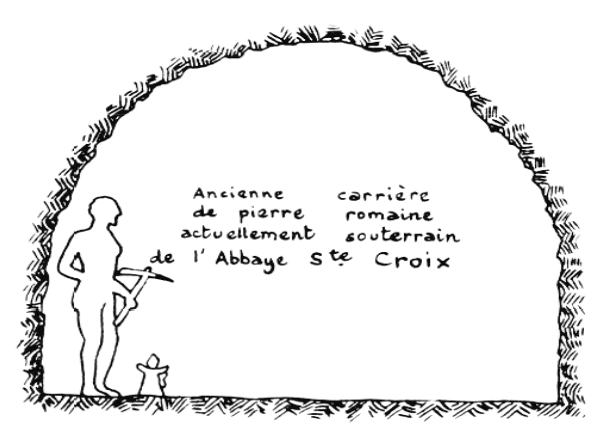




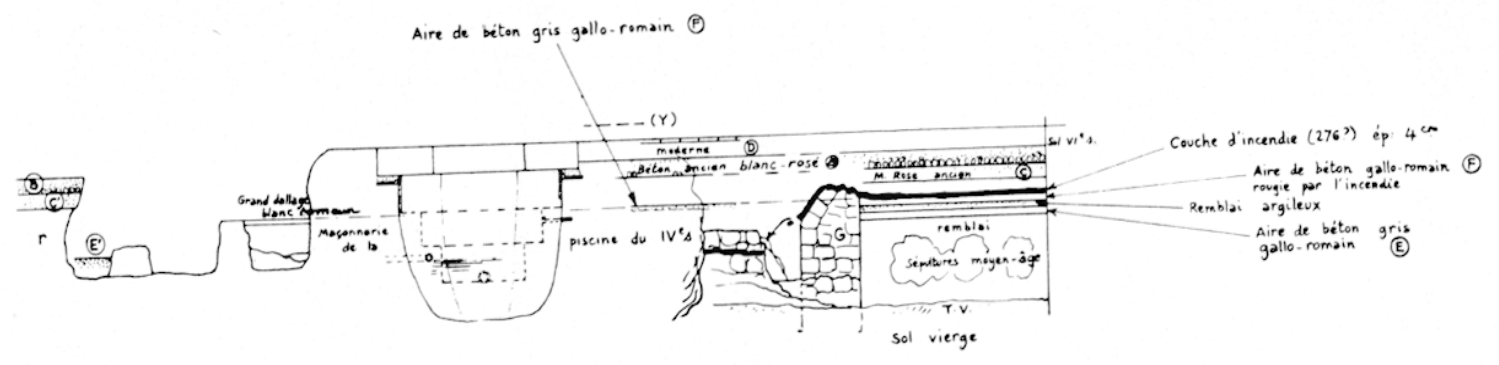

$\begin{array}{lll}0 & 1-2 & 3\end{array}$

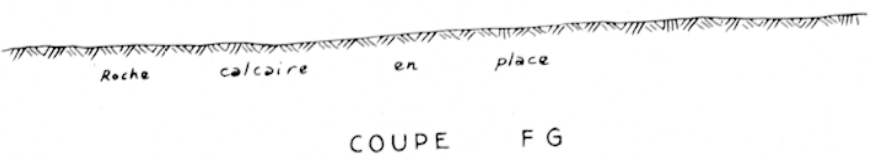

Pl. VI. - Coupe nord-sud de la cella baptismale au centre.

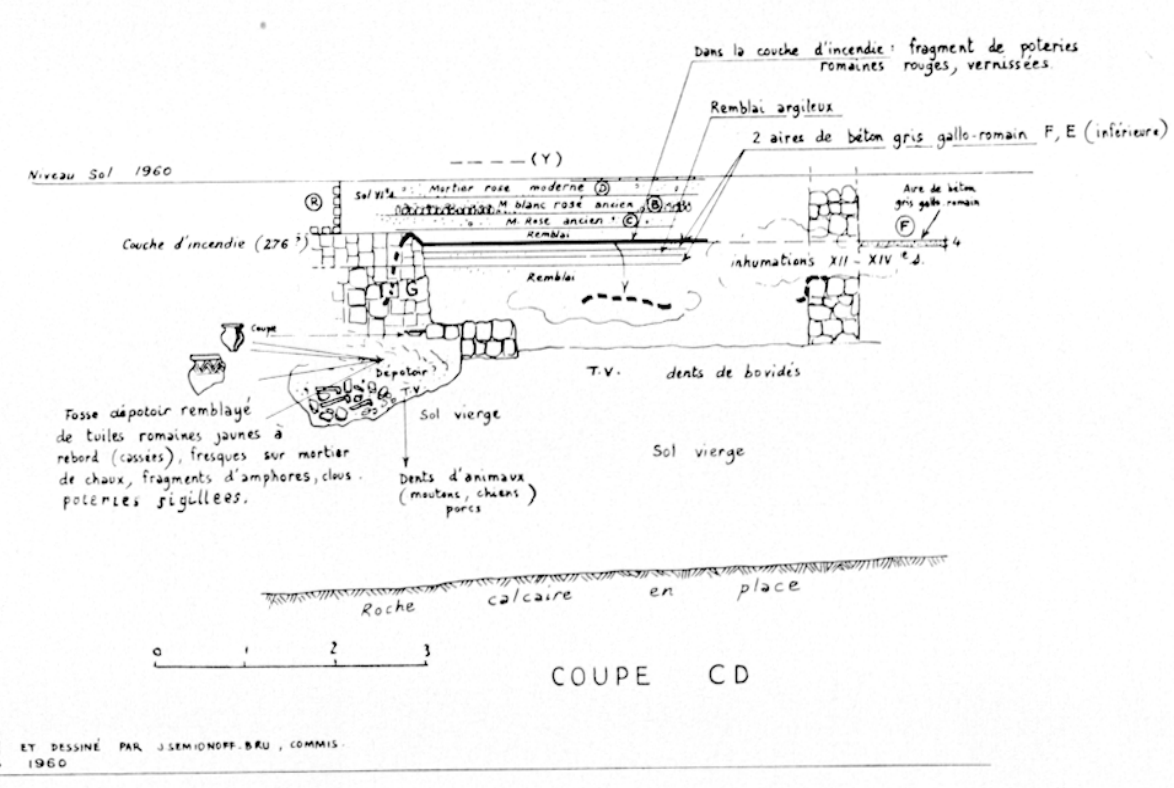

Fl. VII. - Coupe est-ouest de la cella baptismale, à mi-chemin entre la piscine et le mur sud. 